Article

\title{
Error Budget in the Validation of Radiometric Products Derived from OLCI around the China Sea from Open Ocean to Coastal Waters Compared with MODIS and VIIRS
}

\author{
Jun Li ${ }^{1}$, Cédric Jamet ${ }^{2}{ }^{\circledR}$, Jianhua Zhu ${ }^{1}$, Bing Han ${ }^{1, *}$, Tongji Li ${ }^{1}$, Anan Yang ${ }^{1}$, \\ Kai Guo ${ }^{1}$ and Di Jia ${ }^{1}$ \\ 1 National Ocean Technology Center, State Oceanic Administration, Tianjin 300112, China; \\ 1j8697400@126.com (J.L.); besmile@263.net (J.Z.); rsresearch@163.com (T.L.); yangood113@163.com (A.Y.); \\ uiop123hjk1@126.com (K.G.); jid1989@163.com (D.J.) \\ 2 Univ. Littoral Cote d'Opale, Univ. Lille, CNRS, UMR 8187, LOG, Laboratoire d'Océanologie et de \\ Géosciences, 62930 Wimereux, France; cedric.jamet@univ-littoral.fr \\ * Correspondence: hotrice@sina.com; Tel.: +86-22-2753-6521
}

Received: 5 August 2019; Accepted: 10 October 2019; Published: 16 October 2019

\begin{abstract}
The accuracy of remote-sensing reflectance $\left(R_{r s}\right)$ estimated from ocean color imagery through the atmospheric correction step is essential in conducting quantitative estimates of the inherent optical properties and biogeochemical parameters of seawater. Therefore, finding the main source of error is the first step toward improving the accuracy of $R_{r s}$. However, the classic validation exercises provide only the total error of the retrieved $R_{r s}$. They do not reveal the error sources. Moreover, how to effectively improve this satellite algorithm remains unknown. To better understand and improve various aspects of the satellite atmospheric correction algorithm, the error budget in the validation is required. Here, to find the primary error source from the OLCI $R_{r s}$, we evaluated the OLCI $R_{r s}$ product with in-situ data around the China Sea from open ocean to coastal waters and compared them with the MODIS-AQUA and VIIRS products. The results show that the performances of OLCI are comparable to those MODIS-AQUA. The average percentage difference (APD) in $R_{r s}$ is lowest at $490 \mathrm{~nm}(18 \%)$, and highest at $754 \mathrm{~nm}(79 \%)$. A more detailed analysis reveals that open ocean and coastal waters show opposite results: compared to coastal waters the satellite $R_{r s}$ in open seas are higher than the in-situ measured values. An error budget for the three satellite-derived $R_{r s}$ products is presented, showing that the primary error source in the China Sea was the aerosol estimation and the error on the Rayleigh-corrected radiance for OLCI, as well as for MODIS and VIIRS. This work suggests that to improve the accuracy of Sentinel-3A in the coastal waters of China, the accuracy of aerosol estimation in atmospheric correction must be improved.
\end{abstract}

Keywords: OLCI; MODIS; VIIRS; remote-sensing reflectance $\left(R_{r s}\right)$; error budget; China Sea

\section{Introduction}

The first global chlorophyll-a concentration image from the NASA Coastal Zone Color Scanner (CZCS, 1978-1986) launched efforts to begin conducting optical remote sensing of the world's oceans. Many ocean color sensors have been launched since CZCS, including the NASA Sea-viewing Wide Field-of-view Sensor (SeaWiFS, 1997-2010), the NASA Moderate Resolution Imaging Spectroradiometer (MODIS-T, 1999-present on board the Terra platform, and MODIS-A, 2002-present on board the Aqua platform), the ESA Medium Resolution Imaging Spectrometer (MERIS, 2001-2012), NOAA Visible Infrared Imaging Radiometer Suite (VIIRS, 2011-present on board the Suomi NPP) and the most recent 
sensor, the ESA Sentinel-3 Ocean and Land Color Instrument (OLCI, 2016-present). All data acquired by these sensors have been widely used to study the impact of climate change on marine biomass [1,2] and on the carbon cycle [3-7].

Calibration and validation of the various ocean color products in open-sea and coastal waters are important tasks in ocean color satellite missions [8]. Although the methods for acquiring ocean optical properties from satellite measurements is currently established, improving the accuracy of the products for ocean color satellite mission remains a challenge. The remote sensing reflectance $\left(R_{r s}\right)$ (Table 1) is a well-defined radiometric quantity, and its exact definition is common to multiple space agencies [9]. However, uncertainties in calibration, which affect the quantification of the initial signal recorded at the top-of-atmosphere level, may introduce errors when estimating $R_{r s}$ [10]. Moreover, differences among the atmospheric correction schemes, which affect the magnitude and shape of the retrieved marine signals (i.e., $R_{r s}$ ) [11-13], may also introduce errors when estimating $R_{r s}$ [9]. Most importantly, the differences in $R_{r s}$ values may further affect the subsequent optical (absorption and back-scattering coefficients) and biogeochemical products (i.e., chlorophyll concentration, Kd_490, primary production, etc.) [14], which may induce bias in the studies of the impact of anthropogenic carbon on the climate and environment $[15,16]$. Furthermore, the most critical parameters, such as the inherent optical properties (IOPs) of seawater and biogeochemical parameters, are also estimated from $R_{r s}$. Therefore, achieving highly accurate $R_{r s}$ is also critical for ocean color.

Table 1. Symbols and definitions.

\begin{tabular}{lc}
\hline \multicolumn{1}{c}{ Symbols } & Definitions \\
\hline$L_{t}$ & Total measured radiance \\
$L_{r}$ & Radiance due to the Rayleigh scattering \\
$L_{a}, L_{r a}$ & Contribution of the scattering by the aerosols and the scattering between \\
the aerosols and the air molecules & Rayleigh-corrected radiance \\
$L_{r c}$ & Solar irradiance at the mean Earth-Sun distance \\
$F_{0}$ & Diffuse transmittance of the atmosphere from the surface to the sensor \\
$t_{0}$ & Remote-sensing reflectance \\
$R_{r s}$ & Normalized water-leaving radiance \\
$L_{w n}$ & Water reflectance \\
$\rho_{w}$ & Rayleigh, aerosol, and ozone optical thicknesses \\
$\tau_{r}, \tau_{A}, \tau_{O}$ & Viewing direction \\
$\theta_{0}$ & Rayleigh and aerosol forward scattering probabilities \\
$\eta_{R}, \eta_{A}$ & Aerosol single scattering albedo \\
$\omega_{A}$ & Error of A (any symbols can called A) \\
$\delta \mathrm{A}$ &
\end{tabular}

The latest generation of ocean color remote sensor is the Ocean and Land Color Imager (OLCI), which is on board the Sentinel-3A (S3A) satellite, which was successfully launched by the European Space Agency (ESA) on February 16th, 2016. This satellite features many new capabilities, such as (1) global coverage at 300 m (Full Resolution, FR) or 1200 m (Reduced Resolution, RR) resolution; (2) 21 spectral bands from $400 \mathrm{~nm}$ to $1020 \mathrm{~nm}$; (3) sun glint minimization by tilting the sensor from the nadir. OLCI will quickly become the main remote sensor for studying the open ocean and coastal waters $[17,18]$ because four successive versions of the sensor are planned for launch over the next 10-15 years (OLCI-B, on board the Sentinel-3B has been in space since 25 April 2018).

Since OLCI was launched, only a few works have been performed to validate its products [19-22]. Shen et al. (2017) [19] developed a dual band ratio algorithm to calculate the downwelling diffuse attenuation coefficient at $490 \mathrm{~nm}(\mathrm{Kd}(490))$ for the waters of Lake Taihu with OLCI data and showed that the new OLCI product has a smoother spatial distribution and finer textural characteristics than does the MODIS product and it contained notably higher-quality data. Zibordi et al. (2018) [20] summarized a regional assessment of radiometric data products from OLCI with in-situ data from the ocean color component of the Aerosol Robotic Network (AERONET-OC) and the bio-optical 
mapping of marine properties (BiOMaP) program and revealed that there $R_{r s}$ was systematically underestimated while the aerosol optical thickness was overestimated, explainable by biases in calibration coefficients or poor performance of bright pixel correction. Mograne et al. (2019) [21] validated the OLCI water-leaving reflectance products over two contrasted French coastal waters obtained by five different atmospheric correction algorithms (AC), and discovered that the polymer and C2R-CCAltNets algorithms obtain high performances. Gossn et al. (2019) [22] developed a new atmospheric correction algorithm (BLR-AC) for turbid waters based on the red, near-infrared (NIR) and $1016 \mathrm{~nm}$ bands of OLCI. They presented a comparison with the NASA/SeaDAS and ESA standard atmospheric correction algorithms, showing that the BLR-AC is better than the NASA/SeaDAS and ESA AC, particularly over extremely turbid waters. However, these published OLCI validation studies described only the overall error of OLCI in the region of interest; they did not analyze the error sources. Therefore, there is a need to validate OLCI products in other regions of interest (in our case, the China Sea) and, more importantly, to further analyze the sources of their overall error.

Here, we present a validation of the OLCI- $R_{r s}$ product and compare it with the MODIS and VIIRS-derived $R_{r s}(\lambda)$ products around the China Sea based on in situ measurements and match-up analysis. Then, we further assess the uncertainties, the error budget, and the factors that influence the accuracy of the $R_{r s}$ product.

\section{Theoretical Background}

\subsection{Description of Atmospheric Correction}

The goal of atmospheric correction is to estimate and then remove the atmospheric path radiance contribution. The water-leaving radiance is at most $10-20 \%$ of the total top-of-atmosphere (TOA) radiance in the visible bands (VIS) over open ocean waters, and it can reach $50 \%$ in the red bands over turbid waters. Therefore, atmospheric correction is a critical step for remotely sensed data [11]. For the ocean-atmosphere system, after pre-correcting for gas absorption, whitecaps, and sun glitter on the sea surface, the radiance $\left(L_{t}(\lambda)\right)$ measured by the remote sensor can be decomposed as follows $[11,23,24]$

$$
L_{t}(\lambda)=L_{r}(\lambda)+L_{a}(\lambda)+L_{r a}(\lambda)+t_{0}(\lambda) \cos \theta_{0} F_{0}(\lambda) R_{r s}(\lambda)
$$

where $\lambda$ is the wavelength. $L_{r}(\lambda)$ is the radiance due to Rayleigh scattering, $L_{a}(\lambda)+L_{r a}(\lambda)$ is the contribution of the aerosols to scattering and the scattering between aerosols and air molecules, $t_{0}(\lambda)$ is the diffuse transmittance of the atmosphere from the surface to the sensor, $\theta_{0}$ is the viewing direction, $F_{0}$ is the solar irradiance at the mean Earth-Sun distance, and $R_{r s}(\lambda)$ is the remote-sensing reflectance.

Assuming that the corrections for Rayleigh scattering [25-27], whitecaps [28-30], gas absorption $(\mathrm{O} 3, \mathrm{NO})$ [31,32], and sun glitter [26] have all been made, then the left-hand side of Equation (1) becomes

$$
L_{t}(\lambda)-L_{r}(\lambda)=L_{a}(\lambda)+L_{r a}(\lambda)+t_{0}(\lambda) \cos \theta_{0} F_{0}(\lambda) R_{r s}(\lambda)
$$

The term $L_{a}(\lambda)+L_{r a}(\lambda)$ is the aerosol path radiance $L_{A}(\lambda)$ and the term $L_{t}(\lambda)-L_{r}(\lambda)$ is the Rayleigh-corrected radiance $L_{r c}(\lambda)$. Equation (2) thus becomes

$$
L_{r c}(\lambda)=L_{A}(\lambda)+t_{0}(\lambda) \cos \theta_{0} F_{0}(\lambda) R_{r s}(\lambda)
$$

The purpose of atmospheric correction is to estimate $L_{A}(\lambda)$, the combined aerosol and aerosol-Rayleigh reflectance and to subtract it from the left-hand side of Equation (2).

Over open ocean waters, the $L_{A}(\lambda)$ estimation is based on the hypothesis of a black ocean in the near-infrared (NIR) bands [23]. Over turbid waters, this hypothesis is no longer valid; thus, the contribution of the ocean to the NIR must be estimated to accurately estimate $R_{r s}$ in the visible (VIS) bands [11,12,33]. 
In this study, we focused on the standard OLCI radiometric product obtained with the standard OLCI atmospheric correction algorithm and the MODIS-AQUA and VIIRS radiometric products obtained with the NASA standard atmospheric correction algorithm [24]. The latter algorithm has been extensively validated worldwide $[13,14,34,35]$. The hypotheses for the standard OLCI atmospheric correction [36,37] are similar to those of NASA MODIS/VIIRS atmospheric correction [23,24,38,39].

The standard OLCI atmospheric correction algorithm first retrieves the suspended particulate matter (SPM) by assuming the water reflectance $\left(\rho_{w}(\lambda)\right)$ and the single scattering aerosol reflectance $\left(\rho_{a s}(\lambda)\right)$ in the NIR bands based on the black ocean hypothesis. Then, the initial SPM is used to get an initial estimate of $\rho_{w}(\lambda)$ and $\rho_{a s}(\lambda)$ in the NIR bands via an empirical relationship [37]. Finally, the $\rho_{a s}(\lambda)$ in the NIR bands is used to get $\rho_{w}(\lambda)$ in the VIS bands by accounting for the multiple scattering of air molecules and aerosols [36] using Equation (3).

To compare the OLCI product with the MODIS-AQUA and VIIRS $R_{r s}$, we first present a brief description of the standard NASA atmospheric correction algorithm. This algorithm is described in Bailey et al. (2010) [24]. First, the black-pixel assumption is used for both NIR bands to obtain the first initial $R_{r s}(\lambda)$ estimation [23]. Second, Equation (3) is used to obtain the initial estimate of $R_{r s}(\lambda)$ in the NIR bands. Third, the initial $R_{r s}(\lambda)$ is used to obtain an initial estimate of the chlorophyll concentration by using a bio-optical model. Fourth, this chlorophyll concentration is used to obtain the absorption $(a(\lambda))$ and backscatter coefficients $\left(b_{b}(\lambda)\right)$ at the NIR bands via an empirical relationship [24,38]. Fifth, $\mathrm{a}(\lambda)$ and $b_{b}(\lambda)$ in the NIR bands are then used to obtain $R_{r s}(\lambda)$ in the NIR bands and these quantities are used to remove the non-zero $R_{r s}(N I R)$ contribution to $L_{r c}(\lambda)$ from the NIR bands. Finally, this process is repeated until $R_{r s}(N I R)$ convergence to obtain the $R_{r s}(\lambda)$ in all bands.

To summarize, the general flow of these algorithms is as follows:

Step 1. Estimate $R_{r s}(\lambda)$ (or equivalently $\rho_{w}(\lambda)$ ) at the NIR reference wavelengths using the iterative model $[24,38,40]$ so that the non-zero water-leaving radiance can be removed from the TOA signal, leaving only the aerosol reflectance as the contribution to $L_{A}(\lambda)$.

Step 2. The aerosol reflectance at the NIR bands is used to estimate the aerosol properties and extrapolate aerosol reflectance to the VIS bands. Then the aerosol reflectance can be removed from the TOA signal, leaving the $R_{r s}(\lambda)$ (or equivalently $\rho_{w}(\lambda)$ ) in the VIS bands.

In the iterative model, the difference between the real $R_{r s}(N I R)$ and the estimated $R_{r s}(N I R)$ is called the error of the iterative model, and it stems from the error that occurs when estimating $L_{A}(N I R)$ and is later transferred to $L_{A}(\lambda)$ in the VIS bands $\left(L_{A}(V I S)\right)$, leading to inaccurate $R_{r s}(\lambda)$ in the VIS bands $\left(R_{r s}(V I S)\right)$.

The aerosol lookup tables (LUTs) used in the atmospheric correction are obtained from simulations of the radiative transfer and take a given number of aerosol models into account $[23,33,36]$. These estimated aerosol LUTs are ideal, but they may differ from the values observed over the ocean, especially over coastal waters. The difference between the real $L_{A}(V I S)$ and the estimated $L_{A}(V I S)$, which we term the error of the aerosols LUTs, also has an impact on the final $R_{r s}(V I S)$ estimation.

Thus, Step 1 of the algorithms depends on the accuracy of the iterative model used to estimate the aerosol properties in the NIR bands, while Step 2 depends on the accuracy of the aerosol LUTs, which are used to extrapolate the aerosol reflectance to the VIS bands. Note that the iterative model and the aerosol LUTs algorithms differ between ESA and NASA, although their general principles are similar.

\subsection{Error Budget}

To improve the product accuracy for ocean color satellites, it is necessary to not only determine the total error but also to find the most algorithm component that contributes the most to the total error. The error budget decomposes the total error into sub-error categories and then compares the sub-errors to obtain the maximal error contribution. Therefore, calculating the error budget is an essential part of the validation.

If the measurement result is determined by a functional relation from other quantities, rather than directly measured, that function or model should represent not only the physical/bio-optical laws 
but also the measurement process. In particular, it should include all the quantities that may have a significant impact on the uncertainty of the measurement result [41]. Here, we introduce an error budget model that represents both the physical/bio-optical laws and the measurement processes and apply it to estimate the error budget of the $R_{r s}$-derived product [42].

If the result (C) includes two independent parts, such as A and B. The error of $C$ is

$$
\delta C \approx \delta A+\delta B
$$

If the function is given as

$$
q=x+\ldots+z-(u+\ldots+w)
$$

then the error budget is

$$
\delta q \approx \delta x+\ldots+\delta z+\delta u+\ldots+\delta w,
$$

where $q$ is the result; $x, z, u$, and $w$ are function quantities; $\delta q$ is the error of the result; and $\delta x, \delta z, \delta u$, and $\delta w$ are the error of quantities [42].

If the function is given as

$$
q=B x
$$

with B, being a constant. Then the error budget is

$$
\delta q \approx|B| \delta x
$$

where $q$ is the result, $x$ is the quantity, $\delta q$ is the error of the result, and $\delta x$ is the error of the quantity [42].

\subsubsection{Total Error of the Satellite Product}

With the in-situ data and match-up procedures, the total difference in $R_{r s}(\lambda)$ between the in-situ data and the satellite product can be obtained in the VIS bands, for example, the absolute percentage difference (APD, Equation (25)) and the bias (Equation (24)). The in-situ data and the satellite product are independent, according to Equation (4); therefore, the difference between in-situ data and the satellite product can be obtained by

$$
\delta E_{\text {insitu-satellite }}=\delta E_{\text {insitu }}+\delta E_{\text {satellite }}
$$

where $\delta E_{\text {insitu-satellite }}$ is the difference between the in-situ data and a satellite-derived product, $\delta E_{\text {insitu }}$ is the error of the in-situ data (also named the uncertainty on the measurement of the in-situ data), $\delta E_{\text {satellite }}$ is the error of the satellite-derived product. Then, we can calculate the error of the satellite-derived product in the VIS and NIR bands.

Because the error of in-situ data is independent of the satellite measurement, the total error of the satellite-derived product can be computed as

$$
\delta R_{r s-\text { satellite }}=\delta R_{r s-i n s i t u-\text { satellite }}-\delta R_{r s-\text { insitu }}
$$

where $\delta R_{r s-i n s i t u-s a t e l l i t e}$ is the difference between the in situ and satellite-derived $R_{r s}, \delta R_{r s-i n s i t u}$ is the error of the in situ $R_{r s}$, and $\delta R_{r s-s a t e l l i t e}$ is the error of satellite-derived $R_{r s}$.

\subsubsection{Decomposition of the Total Error}

For NASA and OLCI atmospheric correction algorithms, $R_{r s}(\lambda)$ can be derived using the equation

$$
R_{r s}(\lambda)=\frac{L_{r c}(\lambda)-L_{A}(\lambda)}{t_{0}(\lambda) \cos \theta_{0} F_{0}(\lambda)}
$$


For a given band, when the observation geometry and aerosol type are known, then $t_{0}(\lambda) \cos \theta_{0} F_{0}(\lambda)$ is also known, and can be considered a constant [43]. Then, the error of $R_{r s}(\lambda)$ can be derived using Equations (5)-(8), leading to

$$
\delta R_{r s}(\lambda)=\frac{\delta L_{r c}(\lambda)+\delta L_{A}(\lambda)}{\left|t_{0}(\lambda) \cos \theta_{0} F_{0}(\lambda)\right|}
$$

Thus, the error of $R_{r s}(\lambda)$ includes two parts: the error of $L_{r c}(\lambda)$, which is called the error of the Rayleigh-corrected radiance and the error of $L_{A}(\lambda)$, which includes the error of the iterative model and the aerosol LUTs.

\subsubsection{Error of the Iterative Model}

For the NASA and OLCI AC algorithms, $R_{r s}(N I R)$ is estimated using an iterative model, and the error of $R_{r s}(\lambda)$ is the difference between the $R_{r s}(N I R)$ from the iterative model and the $R_{r s}(N I R)$ from the in-situ data. Thus, the error of $R_{r s}(N I R)$ is

$$
\delta R_{r s}(N I R)=R_{r s-i t e}(N I R)-R_{r s-t r u e}(N I R),
$$

where $\delta R_{r s}(N I R)$ is the error of $R_{r s}(\lambda)$ at NIR bands, $R_{r s-i t e}(N I R)$, the $R_{r s}(\lambda)$ from the iterative model in the NIR bands, and $R_{r s-t r u e}(N I R)$, the true/in situ $R_{r s}(\lambda)$ in the NIR bands.

Because the error budget relies on the calculation/iterative process, by determination the $\delta R_{r s}(N I R)$, the error budget of the error of the iterative model is calculated as follows:

(a) The error on $R_{r s}(N I R)$ is passed to $L_{A}(N I R)$ using Equation (11), and the error of $L_{A}(N I R)$ due to the iterative model $\left(\delta L_{A-i t e}(N I R)\right)$ is

$$
\delta L_{A-i t e}(N I R)=\left|t_{0}(N I R) \cos \theta_{0} F_{0}(N I R)\right| \delta R_{r s}(N I R) .
$$

(b) Considering the laws of aerosol radiance in atmospheric correction algorithms $[23,33,44]$, $L_{A}(\lambda)$ can be derived as

$$
L_{A}(\lambda)=L_{A}(N I R) \times\left(\frac{\lambda_{0}}{\lambda}\right)^{\alpha},
$$

where $\alpha$ is the Ångström exponent or Ångström coefficient, which is derived from aerosol LUTs using the aerosol optical thickness $\tau$.

For a given band and a known aerosol type, $\left(\frac{\lambda_{0}}{\lambda}\right)^{\alpha}$ is constant. Then, $\delta L_{A-i t e}(N I R)$ is passed to $L_{A}(V I S)$, and the error of $L_{A}(V I S)$ from the iterative model $\left(\delta L_{A-i t e}(N I R)\right)$ can be derived using Equations (4)-(7)

$$
\delta L_{A-i t e}(V I S)=\delta L_{A-i t e}(N I R)\left|\left(\frac{\lambda_{N I R}}{\lambda_{V I S}}\right)^{\alpha}\right|=\left|t_{0}(N I R) \cos \theta_{0} F_{0}(N I R)\right| \delta R_{r S}(N I R) *\left|\left(\frac{\lambda_{N I R}}{\lambda_{V I S}}\right)^{\alpha}\right|
$$

(c) $\delta L_{A-i t e}(V I S)$ is passed to $R_{r s}(V I S)$ using Equation (10), and the error of $R_{r s}(V I S)$ from the iterative model $\left(\delta R_{r s-i t e}(V I S)\right)$ is

$$
\delta R_{r s-i t e}(V I S)=\frac{\delta L_{A-i t e}(V I S)}{t_{0}(V I S) \cos \theta_{0} F_{0}(V I S)}=\delta R_{r s}(N I R) * \frac{F_{0}(N I R)}{F_{0}(V I S)} *\left|\left(\frac{\lambda_{N I R}}{\lambda_{V I S}}\right)^{\alpha}\right| * \frac{t_{0}(N I R)}{t_{0}(V I S)} .
$$

where $\delta R_{r s-i t e}(\lambda)$ is the error of the iterative model in the VIS bands.

Because $t_{o}(\lambda)$ is not included in the L2 standard products, it can be obtained from [45]

$$
t_{o}(\lambda)=\exp \left(\frac{-\left[\left(1-\eta_{R}(\lambda)\right) \tau_{r}(\lambda)+\left(1-\eta_{A}(\lambda) \omega_{A}(\lambda)\right) \tau_{A}(\lambda)+\tau_{O}\right]}{\cos \left(\theta_{0}\right)}\right)
$$


where $\tau_{r}(\lambda), \tau_{A}(\lambda)$, and $\tau_{O}$ are the Rayleigh, aerosol, and ozone optical thicknesses, respectively; $\omega_{A}(\lambda)$ is the aerosol single scattering albedo; and $\eta_{R}(\lambda)$ and $\eta_{A}(\lambda)$ are the Rayleigh and aerosol forward scattering probabilities, respectively. The $\tau_{r}(\lambda)$ value was computed using Bodhaine et al. (1999) [27]. The value of $\tau_{O}$ was taken as a constant equal to 0.008 . The value $\eta_{R}(\lambda)$ was also taken as a constant equal to 0.5 , while $\eta_{A}(\lambda) \omega_{A}(\lambda)$ was allowed to spectrally vary from 0.89 at $412 \mathrm{~nm}$ to 0.86 at $670 \mathrm{~nm}$. The value $\theta_{0}$ was extracted from the OLCI L2 radiometric product, and from the orbitons for VIIRS and MODIS. The value of $\tau_{A}(\lambda)$ was extracted from the $\mathrm{L} 2$ standard products.

\subsubsection{Error of the Aerosol LUTs and the Rayleigh-Corrected Radiance}

Given the total error of the satellite-derived product (Equation (10)) and the error of the iterative model (Equation (17)), the error of the aerosol LUTs and the error of the Rayleigh-corrected radiance can be calculated using Equation (4). The error of the aerosol LUTs and the Rayleigh-corrected radiance is

$$
\delta R_{r s-L U T s}(\lambda)+\delta L_{r c}(\lambda)=\delta R_{r s-\text { satellite }}(\lambda)-\delta R_{r s-i t e}(\lambda)
$$

where $\delta R_{r s-L U T s}(\lambda)$ is the error of the aerosol LUTs, and $\delta L_{r c}(\lambda)$ is the error of Rayleigh-corrected radiance. The error of $L_{r c}(\lambda)$ includes the errors of both $L_{t}(\lambda)$ and $L_{r}(\lambda)$.

\section{Data and Method}

\subsection{In-Situ Data}

The in-situ data were collected in the coastal and offshore waters of the China Sea (see Figure 1 and Table 2). The stations used during the four campaigns were conducted around the Bo Sea (BoS), Yellow Sea (YS), East China Sea (ECS), the Pearl River Estuary (PRE), and South China Sea (SCS); these stations cover most of the China Sea. The $R_{r s}(\lambda)$ were obtained using two above-water optical instruments, SAS and ASD, following the NASA optical protocols [46]. The SAS and ASD were calibrated before and after each campaign, and the $R_{r s}(\lambda)$ (unit $=\mathrm{sr}^{-1}$ ) were estimated from the in situ radiometric parameters using the R06 approach $[47,48]$

$$
R_{r s}(\lambda)=\frac{L_{t}(\lambda)-\rho L_{s k y}(\lambda)}{E_{s}(\lambda)}
$$

where $L_{t}(\lambda)$ is the total radiance, $L_{s k y}(\lambda)$ is the sky irradiance, $E_{s}(\lambda)$ is the total irradiance, $\lambda$ is the wavelength of incident light, and $\rho$ is the Fresnel reflectance of the air-water interface ( $\rho$ is a function of wind speed and cloud cover). Finally, a residual sun glint or white offset correction ([a* $R_{r s}(780)-$ $\left.\left.R_{r s}(720)\right] / \mathrm{a}-\right)$ was implemented with $\mathrm{a}=2.35$ [48]. The spectral backscattering coefficient $\left(\mathrm{b}_{\mathrm{b}}, \mathrm{m}^{-1}\right)$ using Hydroscatt-6 (HS6) [49] and the spectral absorption coefficient $\left(\mathrm{a}, \mathrm{m}^{-1}\right)$ using AC9 [49] were collected during only two campaigns (YS, ECS\&SCS).

\subsection{Quality Control of the In Situ Data}

Quality control of the in-situ data was essential because the in-situ data were considered as the sea-truth and because we sampled the $R_{r s}$ values using two different radiometers.

\subsubsection{Consistency of Multiple Measurements}

Each in situ $R_{r s}$ was measured three times (three replicates) at each sampling station. The samples were excluded if the coefficient of variability $\left(\mathrm{CV}=\right.$ standard deviation $\left(R_{r s}\right) /$ mean $\left.\left(R_{r s}\right)\right)$ of the three $R_{r s}$ spectra at $490 \mathrm{~nm}$ at any given station was higher than $5 \%$ (Figure 2). Based on this threshold, 18 stations were removed. 


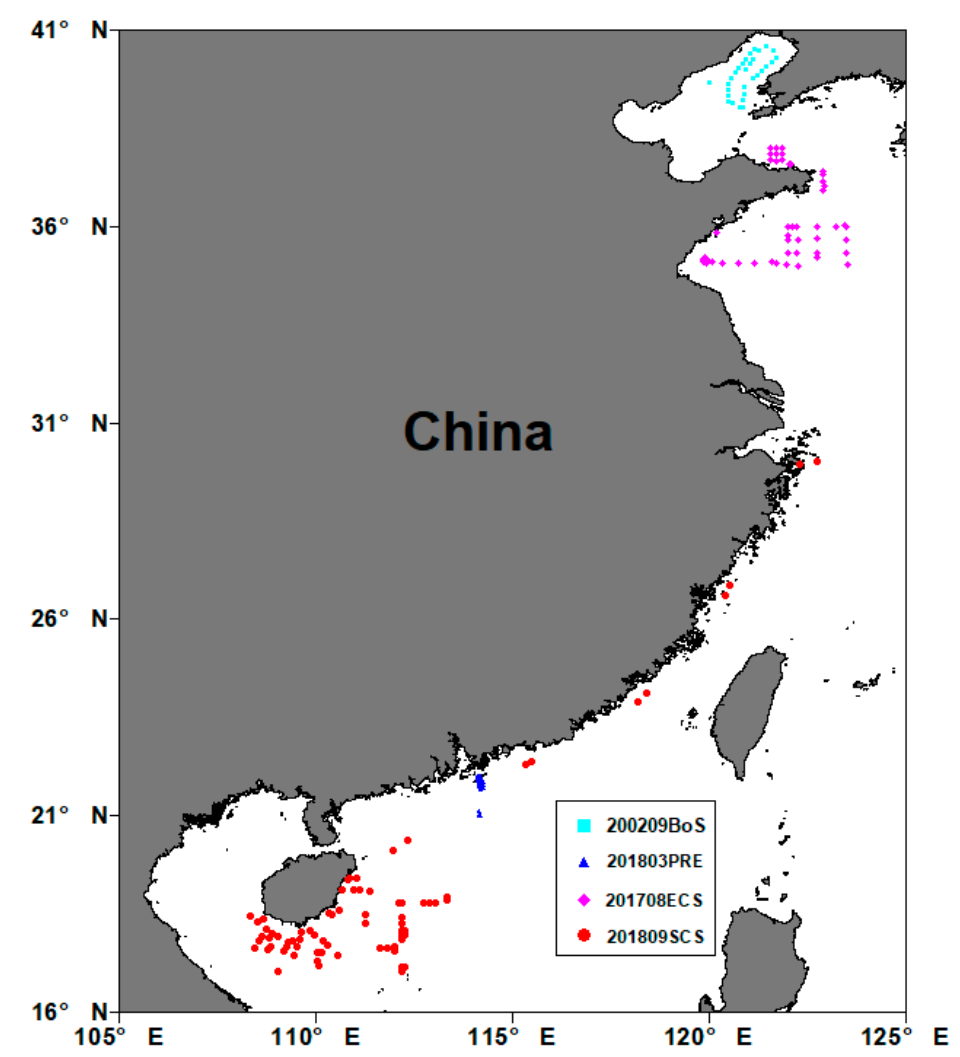

Figure 1. Stations of the China Sea used in the study.

Table 2. Location, period, number, and source of $R_{r s}$ samples used in the study.

\begin{tabular}{cccc}
\hline Period & Place & Number of Stations & Source of $\boldsymbol{R}_{\boldsymbol{r s}}$ \\
\hline 2002.09 & BoS & 30 & ASD \\
2017.08 & YS & 76 & SAS \\
2018.03 & PRE & 30 & SAS \\
2018.09 & ECS\&SCS & 74 & SAS \\
\hline
\end{tabular}

\subsubsection{Removal of the Surface-Reflected Radiance}

The surface-reflected radiance (mainly due to sky glint because direct sun glint is usually weak with measurement geometry) is recognized as a major sources of uncertainty [50,51]; thus, a station was discarded when the $\rho L_{s k y} / L_{t}$ exceeded $50 \%$, [50,52]. Based on this threshold, eight stations were removed.

\subsubsection{Comparison with an IOP Model}

$R_{r s}$ can also be estimated from the IOPs of seawater, i.e., the backscattering (obtained here using the HS6 instrument) and absorption coefficients (using the AC9 instrument). The $R_{r s}$ can be modeled using the IOPs, and the modeled $R_{r s}$ values can be compared to the ASD/SAS in situ $R_{r s}$ measurements [53,54] using the equation

$$
R_{r_{-} I O P}(\lambda)=\left(\frac{t^{2}}{n_{w}^{2}}\right) \sum_{i=1}^{2} g_{i}\left(\frac{b_{b}(\lambda)}{b_{b}(\lambda)+a(\lambda)}\right)^{i}
$$

The absolute difference between the in situ $R_{r s}$ and the modeled $R_{r s}$ is calculated as

$$
\operatorname{diff}=\left|\frac{R_{r S_{-} A O P}-R_{r S_{-} I O P}}{R_{r S_{-} A O P}}\right|
$$




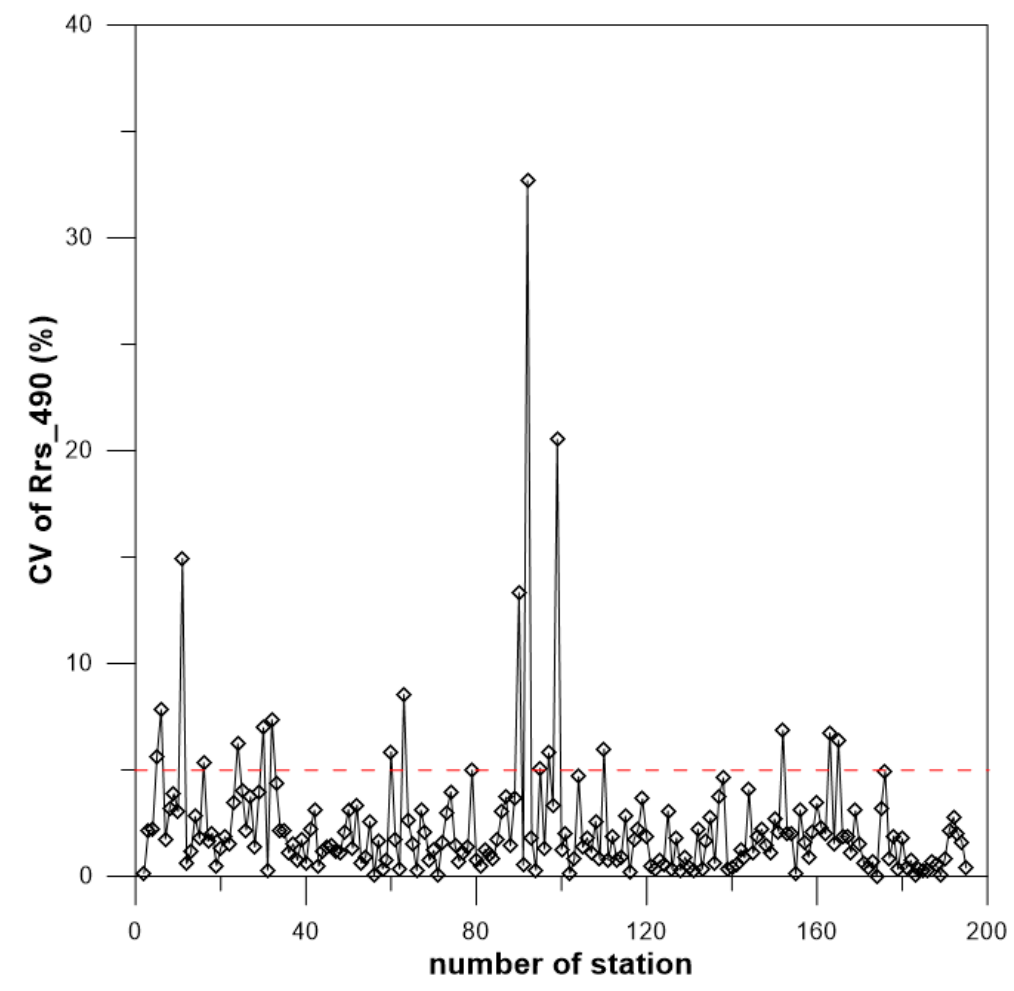

Figure 2. $\mathrm{CV}\left(R_{r S}\right)$ for all stations.

The coefficients of the model presented in Equation (22) are from the GSM model [55,56]. If diff was larger than $30 \%$, the corresponding in situ measurement was discarded. The PRE and BoS campaigns were not included in this closure exercise because no IOPs measurements were collected for these areas due to the lack of AC9 and HS6 data. The $R_{r s}$ values from 17 stations were removed based on this method. The remaining $R_{r s}$ values are depicted in Figure 3. Some stations were kept when only one band exceeded the threshold, which is the case for stations where the diff was above $30 \%$ at 650 and $676 \mathrm{~nm}$. The mean absolute percentage difference (APD, Equation (25)) and the relative percentage difference (RPD, Equation (26)) between the modeled and in situ $R_{r s}$ values are shown in Figure 3. Overall, there is good consistency between the in situ and modelled $R_{r s}$ in the VIS; the APD varies from $11.82 \%(412 \mathrm{~nm})$ to $25.35 \%(676 \mathrm{~nm})$, and the values increase with increasing wavelengths $[57,58]$.

The total number of the discarded stations is 43 (some values were discarded because there were several $R_{r s}$ for a given station). After undergoing this quality control process, the data from 167 stations remained and were used for the match-up exercise.

\subsection{Satellite-Derived Data}

The L2 VIIRS and MODIS-AQUA $R_{r s}$ products (reprocessing version 2018) were downloaded from the NASA Ocean Color website (http://oceancolor.gsfc.nasa.gov/). OLCI L2 RR $R_{r s}$ product (version 2.23) was downloaded from EUMETSAT website (https://coda.eumetsat.int/).

\subsection{Match-Up Procedures}

The match-up analyses and quality control were performed for the $R_{r s}$ values from VIIRS, MODIS, and OLCI radiometric products. First, strict rules for time interval and spatial distance to the match-up data were applied. We selected the mean $R_{r s}$ values over a $0.034 \times 0.034$ degree (VIIRS), $0.05 \times 0.05$ degree (MODIS and OLCI RR) rectangle, from the L2 product within a time window of $\pm 3 \mathrm{~h}$. The spatial distance the same as in-situ data, corresponding to about a $5 \times 5$-pixel box near the nadir, but this pixel box size was adjusted at the scan edge to address spatial heterogeneity as suggested by Barnes et al. (2019) [59]. Second, views and solar zenith angles above $60^{\circ}$ and $70^{\circ}$, 
respectively, were removed for all match-up data. Moreover, the L2 flags of the match-up data were applied. The L2 flags for OLCI include INVALID, LAND, CLOUD, CLOUD_AMBIGUOUS, CLOUD_MARGIN, SNOW_ICE, SUSPECT, HISOLZEN, SATURATED, HIGHGLINT, WHITECAPS, AC_FAIL, OC4ME_FAIL, ANNOT_TAU06, RWNEG_O2, RWNEG_O3, RWNEG_O4, RWNEG_O5, RWNEG_O6, RWNEG_O7, RWNEG_O8, and the $490 \mathrm{~nm}$ reflectance of is below 0.02 . The L2 flags for MODIS and VIIRS include ATMFAIL, LAND, HIGLINT, HILT, HISATZEN, STRAYLIGHT, CLDICE, COCCOLITH, HISOLZEN, LOWLW, CHLFAIL, NAVWARN, ABSAER, MAXAERITER, ATMWARN, NAVFAIL [60]. Third, because the accuracy of $R_{r s}(488 / 490)$ is usually the highest [59], a coefficient of variability $\mathrm{CV}(\mathrm{CV}=\mathrm{STD} / \mathrm{mean})$ was calculated for all boxes at $490(488) \mathrm{nm}$ in the space distance was calculated and a match-up was considered valid when the CV was smaller than 0.15 at $490 \mathrm{~nm}$ [60]. Finally, the percentage of valid pixels in each box was checked, and when this percentage was no less than $50 \%$, the mean values of the valid pixels in the box was calculated and compared to the in-situ data.

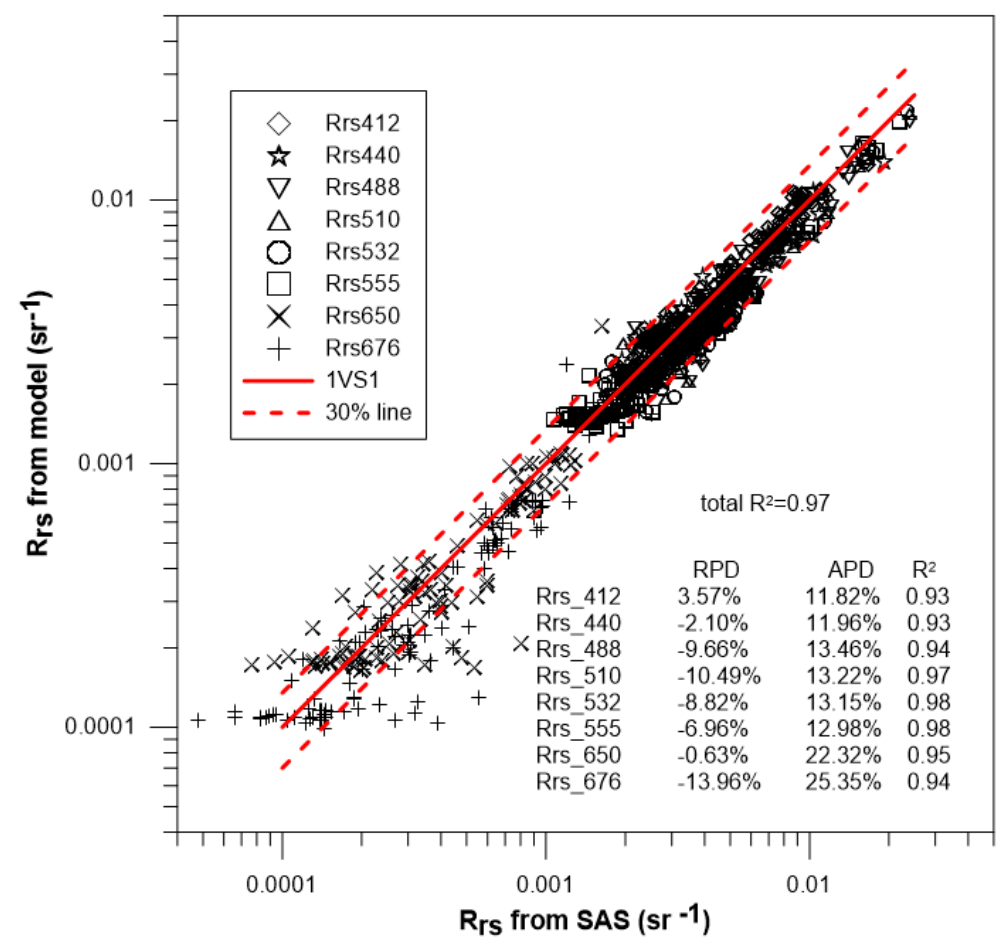

Figure 3. Difference between the in-situ $R_{r s}$ and the $R_{r s}$ estimated from the GSM model using the in-situ IOPs.

\subsection{Statistical Method}

Several statistical parameters were used to evaluate the match-up results. The definitions of these parameters are given below:

The bias:

$$
\text { Bias }=\frac{1}{\mathrm{n}} \sum_{\mathrm{i}=1}^{\mathrm{i}=\mathrm{n}}\left(y_{\mathrm{i}}-x_{\mathrm{i}}\right)
$$

The absolute percentage difference (APD):

$$
\mathrm{APD}=\frac{1}{\mathrm{n}} \sum_{\mathrm{i}=1}^{\mathrm{i}=\mathrm{n}}\left(\left|\frac{y_{\mathrm{i}}-x_{\mathrm{i}}}{x_{\mathrm{i}}}\right|\right) \times 100 \%
$$

The relative percentage difference (RPD):

$$
\mathrm{RPD}=\frac{1}{\mathrm{n}} \sum_{\mathrm{i}=1}^{\mathrm{i}=\mathrm{n}}\left(\frac{y_{\mathrm{i}}-x_{\mathrm{i}}}{x_{\mathrm{i}}}\right) \times 100 \%
$$


The root mean square error (RMSE):

$$
\text { RMSE }=\sqrt{\frac{\sum_{\mathrm{i}=1}^{\mathrm{i}=\mathrm{n}}\left(y_{\mathrm{i}}-x_{\mathrm{i}}\right)^{2}}{\mathrm{n}}}
$$

The unbiased RMS difference $\left(u_{\Delta}\right)$ [61]:

$$
u_{\Delta}=\sqrt{\frac{\sum_{\mathrm{i}=1}^{\mathrm{i}=\mathrm{n}}\left(y_{\mathrm{i}}-x_{\mathrm{i}}+\bar{x}-\bar{y}\right)^{2}}{\mathrm{n}}}
$$

with $y_{\mathrm{i}}$, the ith satellite-retrieved value, $x_{\mathrm{i}}$, the ith in-situ value, and $\mathrm{n}$, the number of match-up data points.

\section{Results}

\subsection{Variability of the In-Situ $R_{r s}$ Data}

The total dataset of $R_{r s}$ for the four campaigns are shown in Figure 4 . The $R_{r s}$ spectra include both open and coastal waters. SCS is mainly composed of open ocean waters [62], while YS and BoS are SPM-dominated waters [63]. We classified the $R_{r s}$ values following the method developed in Wei et al. (2016) [64]. The $R_{r s}$ of the in-situ dataset corresponds to the classes 2-14 and 16 from Wei et al. (2016) [64]. Figure 4 shows a color code that depends on the classes defined by Wei et al. (2016) [64]. The blue plots are typical of open ocean waters (classes 2-4), whose $R_{r s}$ values depend only on phytoplankton. The green spectra correspond to more optically complex waters, including those with CDOM and phytoplankton in the water (classes 5-9). The black spectra correspond to SPM-dominated waters (classes 10-14 and 16). For open ocean waters (blue spectra), we can observe the well-known shape of the spectra with high values of $R_{r s}$ at 410 and $443 \mathrm{~nm}$ and a decreasing magnitude from the blue bands to the NIR. For the intermediate waters (green spectra), we can observe that the highest magnitude is observed in the green bands and that their magnitudes are low in the NIR bands. Due to the high CDOM absorbance in the purple/blue bands, the $R_{r s}$ at 410 and $443 \mathrm{~nm}$ are lower than those in the green bands. In turbid waters (black spectra), the highest magnitude is observed in the yellow bands and high magnitudes also exist in the NIR bands (compared to the open ocean and intermediate waters) due to the strong SPM backscatter. In conclusion, our $R_{r s}$ dataset covers a large set of water types in the China Sea.

The spatial location and the $R_{r s}$ spectra of the match-ups are shown in Figure 5. The number of match-up stations for OLCI, MODIS, and VIIRS are 13, 13, and 15, respectively. Both the intermediate waters (green) and the turbid waters (black) are coastal waters. Figure 5 shows the match-up stations of the three sensors covering the coastal and open ocean waters. The match-up stations of MODIS and VIIRS cover SCS, YS, and BoS. The match-up stations of OLCI cover SCS, ECS, and YS. The $R_{r s}$ from the match-up stations of OLCI and MODIS included all three types of waters. The $R_{r s}$ from the match-up stations of VIIRS included only two water types (open ocean and turbid waters). The match-up stations of three sensors cover most of the China Sea and most of the water types. 

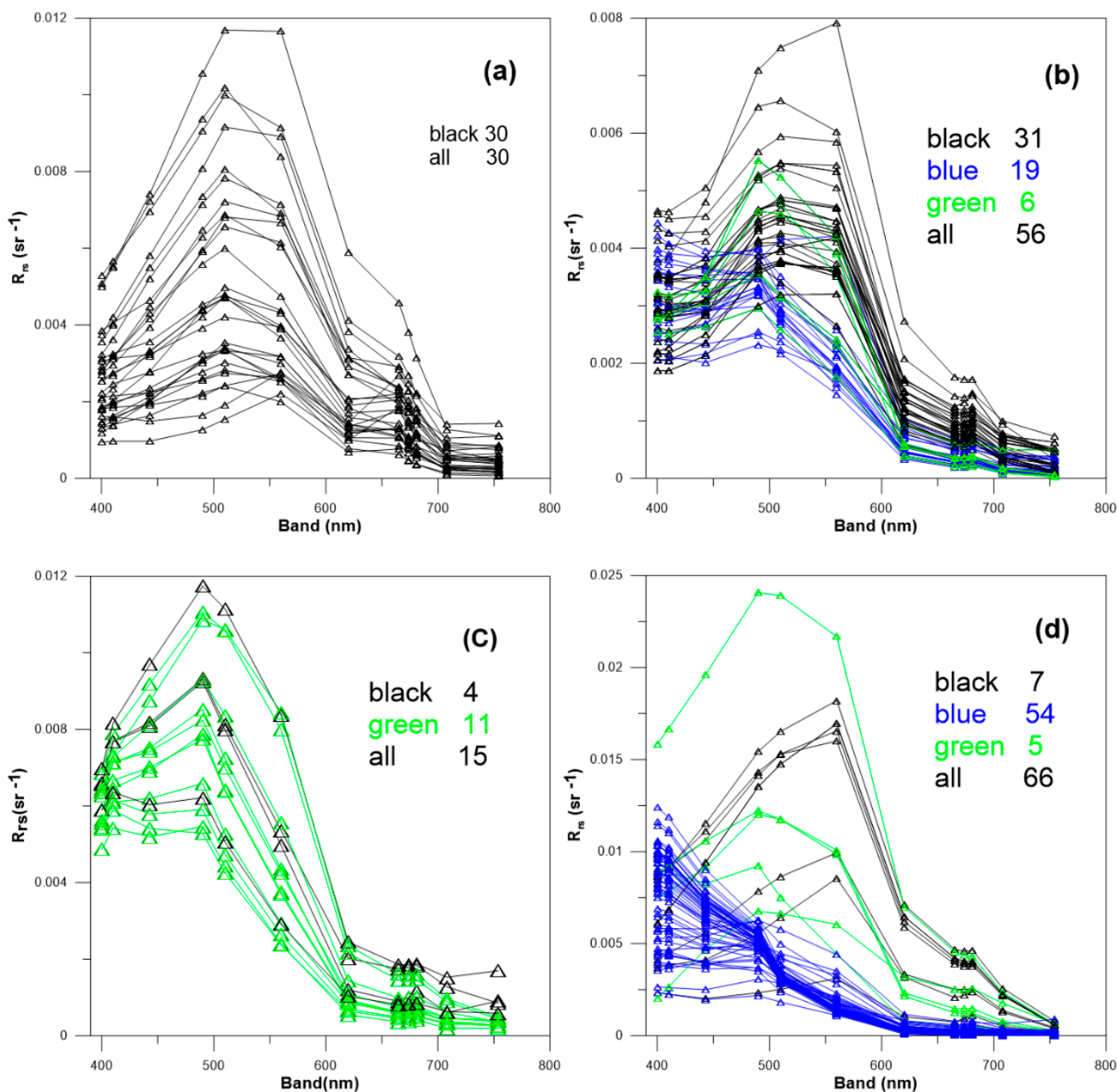

Figure 4. In-situ $R_{r S}$ spectra at OLCI bands: (a) in the BoS, (b) in the YS, (c) in the PRE, (d) in the ECS\&SCS. The blue spectra correspond to the open ocean, the black spectra to the turbid waters, the green corresponds to intermediate waters between open ocean and turbid waters.

\subsection{Validation Results}

Scatterplots showing the relationship between the in situ and satellite-derived $R_{r s}$ are shown in Figure 6 (OLCI) and Figure 7 (VIIRS and MODIS) and the statistical parameters are listed in Table 3. For OLCI, the points of the scatterplots are mainly distributed around the 1:1 line. The scatterplots show that the satellite-derived values are in good agreement with the in situ $R_{r s}$ values, except at 400 and $410 \mathrm{~nm}$, which corresponds to the campaign in PRE (coastal waters; the red circle in Figure 6). The bias values show that the satellite-derived $R_{r s}$ values are under-estimated compared to the in-situ $R_{r s}$, except at 400, 443, 490, and $510 \mathrm{~nm}$. Then, in the visible spectra, the $R_{r s}$ are mainly over-estimated and under-estimated in the NIR (negative bias values). The RMSE and $u_{\Delta}$ are low for all bands, with values below $0.003 \mathrm{sr}^{-1}$, which means that the satellite-derived values are in good agreement with the in situ $R_{r s}$. The highest RMSE value is obtained at $400 \mathrm{~nm}\left(0.003 \mathrm{sr}^{-1}\right)$. The statistical parameters showed that the APDs at 400, 410, 443, 490, 510, 560, 620, 665, 674, 681, 708, and $754 \mathrm{~nm}$ are $43 \%, 30 \%, 23 \%, 18 \%$, $20 \%, 21 \%, 68 \%, 57 \%, 77 \%, 66 \%, 56 \%$, and $79 \%$ for OLCI, respectively. The $R_{r s}$ values at $490 \mathrm{~nm}$ show the lowest APD making it the most accurate band. 

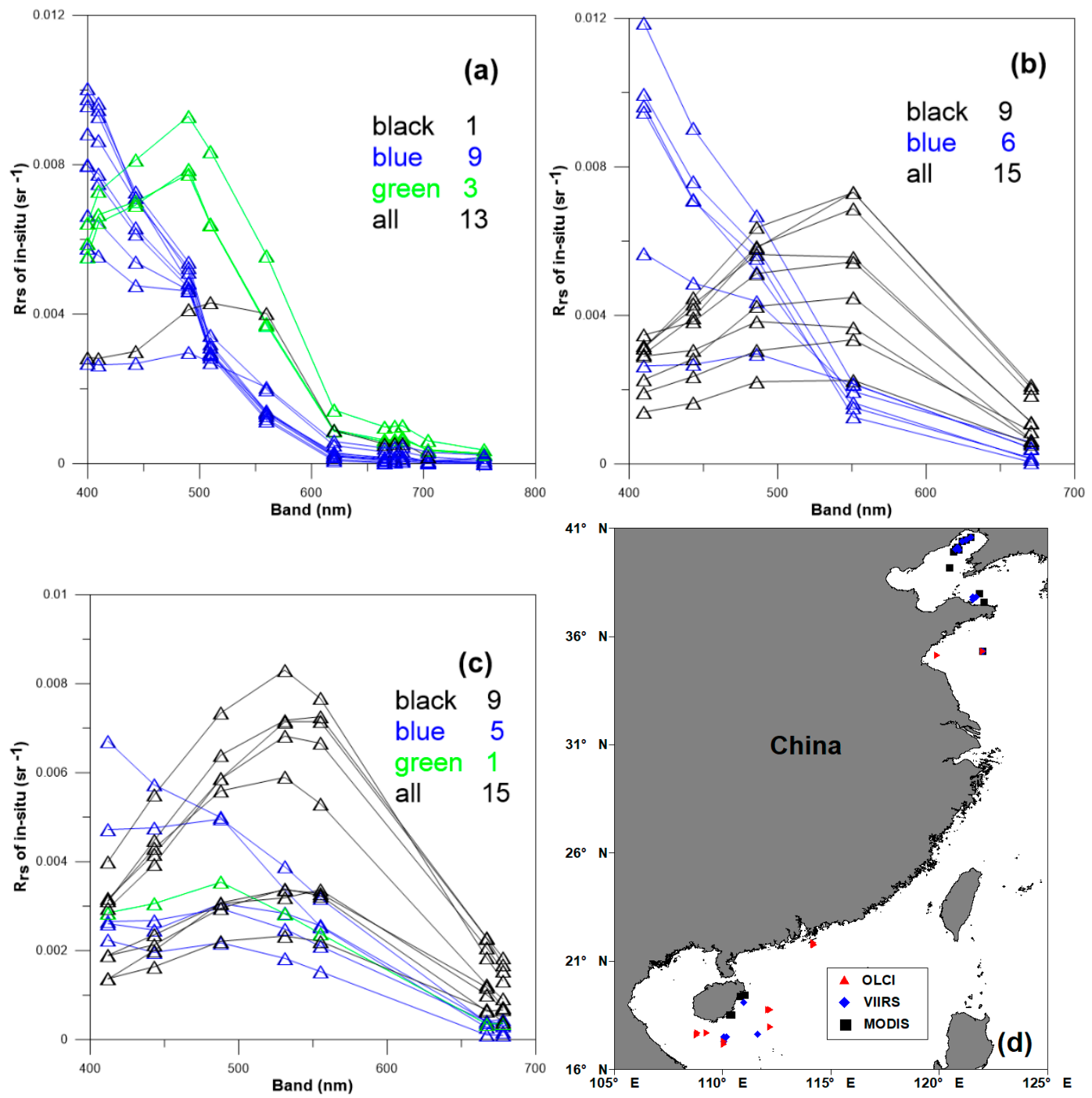

Figure 5. In-situ $R_{r s}$ spectra and the map of match-up stations: (a) OLCI, (b)VIIRS, (c) MODIS, (d) the geographical map with the location of the match-up for each sensor. The color code is same as Figure 4.

The MODIS/VIIRS derived- $R_{r s}$ scatterplots are shown in Figure 7, and the statistical parameters are listed in Table 3. For OLCI, the points of the scatterplots are mainly distributed around the 1:1 line and show that the satellite-derived values are in agreement with the in situ $R_{r s}$ for MODIS/ VIIRS, other than a few some outliers (red circle), where the in situ $R_{r s}$ were collected in BOS (coastal waters). The Bias values showed that the satellite-derived $R_{r s}$ values were under-estimated compared to the in situ $R_{r s}$ in all bands (except at $678 \mathrm{~nm}$ for MODIS, perhaps due to chlorophyll fluorescence). The RMSE and $u_{\Delta}$ are low in all bands, and have values below $0.002 \mathrm{sr}^{-1}$, which means that the satellite-derived values are in good agreement with the in situ $R_{r s}$. The highest RMSE values were obtained at $412 \mathrm{~nm}$ (MODIS) and at $443 \mathrm{~nm}$ (VIIRS). The statistical parameters show that the APDs at 412, 443, 488, 531, 555, 645,667 , and $678 \mathrm{~nm}$ are $39 \%, 30 \%, 26 \%, 19 \%, 19 \%, 48 \%, 32 \%$, and $40 \%$ for MODIS, respectively, while the APDs at $410,443,486,510$, and $671 \mathrm{~nm}$ were $46 \%, 42 \%, 30 \%, 27 \%$, and $36 \%$ for VIIRS, respectively. The $R_{r s}(531)$ and $R_{r s}(551)$ are the most accurate for MODIS and VIIRS, respectively. Although PRE and BOS are located in different regions of the China Sea, their water types (which belong to coastal waters) are similar, and the aerosols are affected by terrestrial sources, which might be the main source of the outliers for these three sensors. 


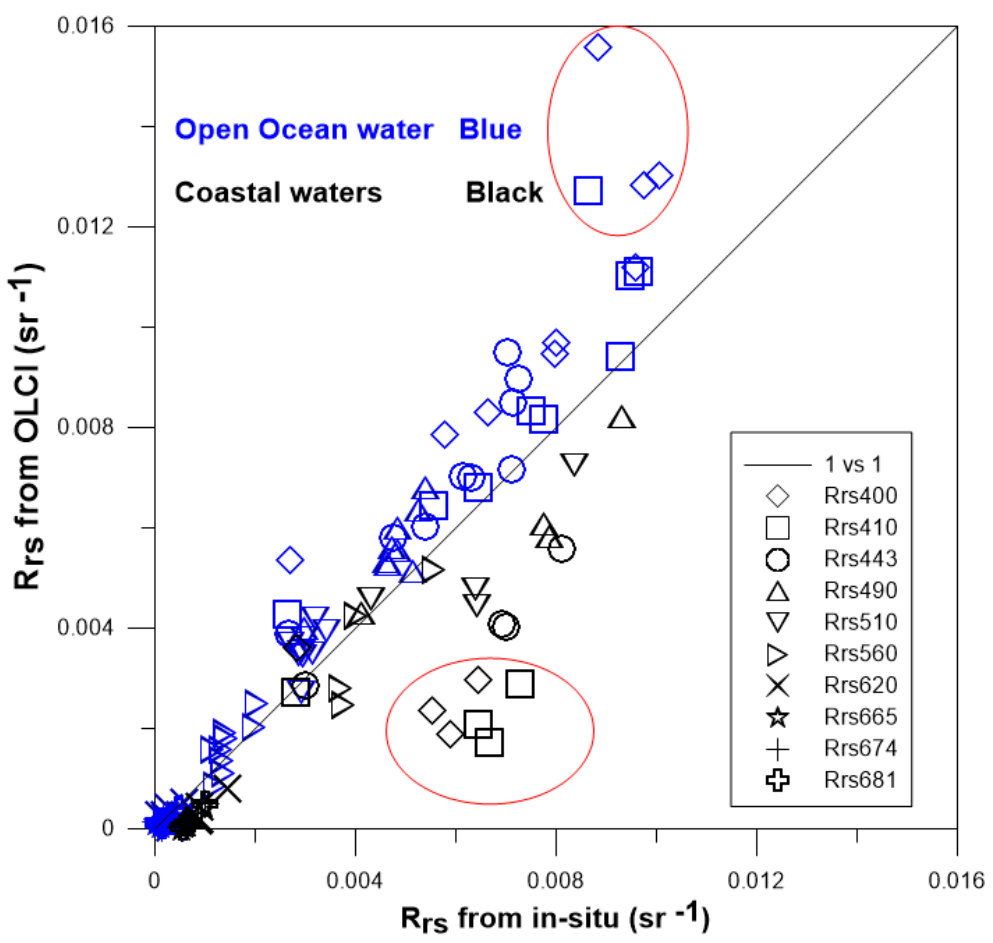

Figure 6. Scatterplot of OLCI-derived versus in situ remote-sensing reflectance in the China Sea, total $\mathrm{R}^{2}=0.83$. The blue scatterplots correspond to the open ocean, the black scatterplots to the coastal waters. The red circles correspond to the outliers for the PRE region (the APD of the outlier points is larger than the mean APD $+/-3^{*}$ sigma of the other points).
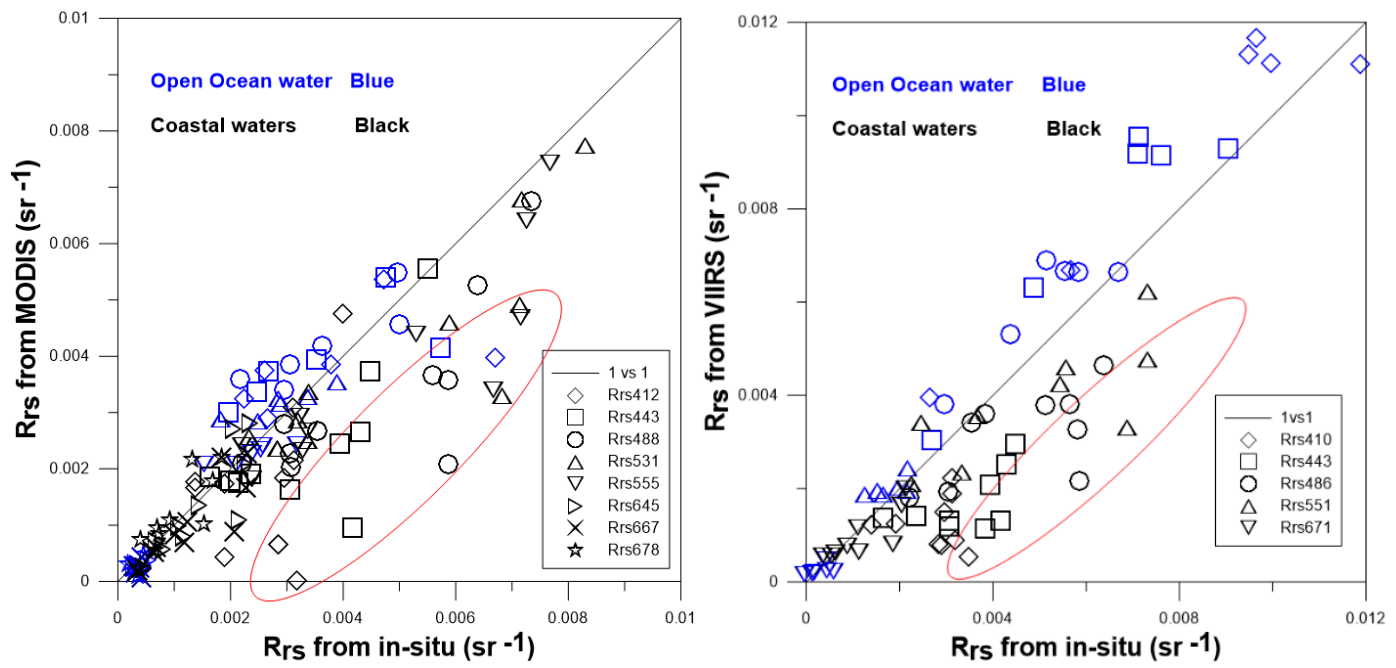

Figure 7. Scatterplot of the satellite-derived versus in situ remote-sensing reflectance in the SCS (left: MODIS-AQUA, total $\mathrm{R}^{2}=0.76$; right: VIIRS, total $\mathrm{R}^{2}=0.80$ ). The color code and the outliers are similar as in Figure 6. The red circles correspond to the outliers for the BoS region.

The spectral variation of the Bias, RMSE, APD, and $u_{\Delta}$ for OLCI, MODIS and VIIRS are shown in Figure 8 . The trend of RMSE, APD, and $u_{\Delta}$ are the same for OLCI, MODIS and VIIRS. The bias of OLCI is positive in the 400,443,490, and $510 \mathrm{~nm}$ bands, which differs from MODIS and VIIRS. The absolute value of the bias for OLCI is lower than that for MODIS and VIIRS in most of the bands (from $410 \mathrm{~nm}$ to $620 \mathrm{~nm}) . R_{r s}(400)$ is the least accurate band for OLCI. Among the three sensors, the RMSE and $u_{\Delta}$ are consistent in term of both trend and value. The $u_{\Delta}$ of OLCI is lower than that of MODIS, and VIIRS in the bands between $490 \mathrm{~nm}$ and $754 \mathrm{~nm}$. The UV band $(400 \mathrm{~nm})$ is the least accurate for OLCI. 
The APD value of OLCI is lower than that of MODIS, and VIIRS in the 412, 443, 490, and $510 \mathrm{~nm}$ bands. The APD of OLCI is higher than for MODIS and VIIRS in the NIR bands (from $600 \mathrm{~nm}$ to $678 \mathrm{~nm}$ ). Although their match-up stations are different, the performance of OLCI is similar to that of MODIS in the visible bands.

Table 3. Statistical parameters of OLCI, MODIS, and VIIRS around the China Sea.

\begin{tabular}{|c|c|c|c|c|c|c|}
\hline Satellite & Product & $\mathbf{n}$ & Bias $\left(\mathrm{sr}^{-1}\right)$ & RMSE $\left(\mathrm{sr}^{-1}\right)$ & APD (\%) & $u_{\Delta}\left(\mathrm{sr}^{-1}\right)$ \\
\hline \multirow{12}{*}{ OLCI } & $R_{r S}(400)$ & 13 & 0.001085 & 0.00300 & 43 & 0.00290 \\
\hline & $R_{r s}(410)$ & 13 & -0.000186 & 0.00252 & 30 & 0.00260 \\
\hline & $R_{r s}(443)$ & 13 & 0.000120 & 0.00166 & 23 & 0.00172 \\
\hline & $R_{r s}(490)$ & 13 & 0.000237 & 0.00107 & 18 & 0.00108 \\
\hline & $R_{r s}(510)$ & 13 & 0.000061 & 0.00092 & 20 & 0.00096 \\
\hline & $R_{r S}(560)$ & 13 & -0.000061 & 0.00052 & 21 & 0.00053 \\
\hline & $R_{r s}(620)$ & 13 & -0.000241 & 0.00036 & 68 & 0.00031 \\
\hline & $R_{r s}(665)$ & 13 & -0.000231 & 0.00030 & 58 & 0.00023 \\
\hline & $R_{r S}(674)$ & 13 & -0.000206 & 0.00029 & 77 & 0.00024 \\
\hline & $R_{r s}(681)$ & 13 & -0.000227 & 0.00030 & 66 & 0.00023 \\
\hline & $R_{r s}(708)$ & 13 & -0.000177 & 0.00016 & 56 & 0.00018 \\
\hline & $R_{r s}(754)$ & 13 & -0.000098 & 0.00012 & 79 & 0.00012 \\
\hline \multirow{8}{*}{ MODIS } & $R_{r S}(412)$ & 15 & -0.000531 & 0.00149 & 39 & 0.00141 \\
\hline & $R_{r s}(443)$ & 15 & -0.000478 & 0.00127 & 30 & 0.00118 \\
\hline & $R_{r S}(488)$ & 15 & -0.000662 & 0.00143 & 26 & 0.00127 \\
\hline & $R_{r S}(531)$ & 15 & -0.000540 & 0.00122 & 19 & 0.00109 \\
\hline & $R_{r s}(555)$ & 15 & -0.000708 & 0.00119 & 19 & 0.00095 \\
\hline & $R_{r s}(645)$ & 15 & -0.000150 & 0.00041 & 48 & 0.00038 \\
\hline & $R_{r s}(667)$ & 15 & -0.000213 & 0.00040 & 32 & 0.00034 \\
\hline & $R_{r s}(678)$ & 15 & 0.000079 & 0.00032 & 40 & 0.00031 \\
\hline \multirow{5}{*}{ VIIRS } & $R_{r s}(410)$ & 15 & -0.000481 & 0.00157 & 47 & 0.00155 \\
\hline & $R_{r s}(443)$ & 15 & -0.000495 & 0.00171 & 42 & 0.00169 \\
\hline & $R_{r S}(486)$ & 15 & -0.000508 & 0.00151 & 30 & 0.00147 \\
\hline & $R_{r s}(551)$ & 15 & -0.000549 & 0.00127 & 27 & 0.00118 \\
\hline & $R_{r S}(671)$ & 15 & -0.000137 & 0.00033 & 36 & 0.00032 \\
\hline
\end{tabular}

\subsection{Difference between Open Ocean and Coastal Waters}

Although the mean bias or APD values differ between the satellites (see Figure 8), we noticed that the satellite-derived $R_{r s}$ has a small difference in the open ocean and a large difference in the coastal water (see Figures 6 and 7). The reason may be the surface-reflected radiance which is one of the main sources of uncertainties in satellite $R_{r s}$ retrievals $[65,66]$. These effects are small in the open ocean with small aerosol loads and much more pronounced in coastal waters with higher aerosol loads, because they strongly depend on the aerosol optical thickness [67]. The phenomenon that the APD of three sensors decreases with increasing band is also the same influencing factor, because the sky radiance reflected from the water surface, which carries uncertainties to the satellite-derived $R_{r s}$, is highest in the blue part of the spectrum [59].

Although the mean bias or APD values differ between the satellites (see Figure 8), we noticed that the satellite-derived $R_{r s}$ were higher than the in situ values in the visible bands over open ocean waters, which is a different situation than coastal waters (Figures 6 and 7). The RPD values from OLCI, MODIS, and VIIRS are shown in Figure 9, showing that the three satellites have similar results and, except for a few points, the RPD values of the $R_{r s}$ are positive over open ocean but negative in coastal waters. 

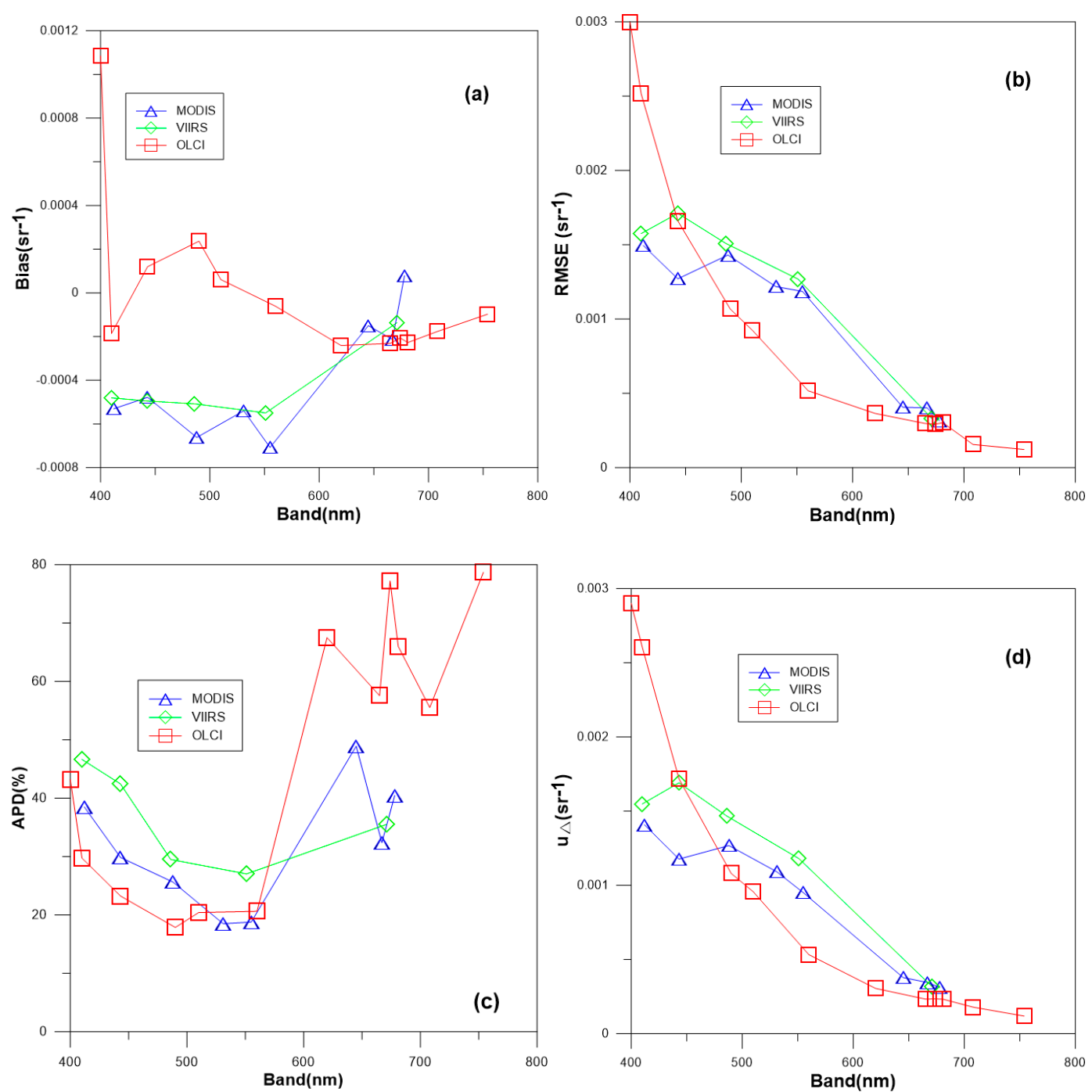

Figure 8. Variation of bias (a), RMSE (b), APD (c), and $u_{\Delta}(\mathbf{d})$ of OLCI, MODIS, and VIIRS with the wavelengths.
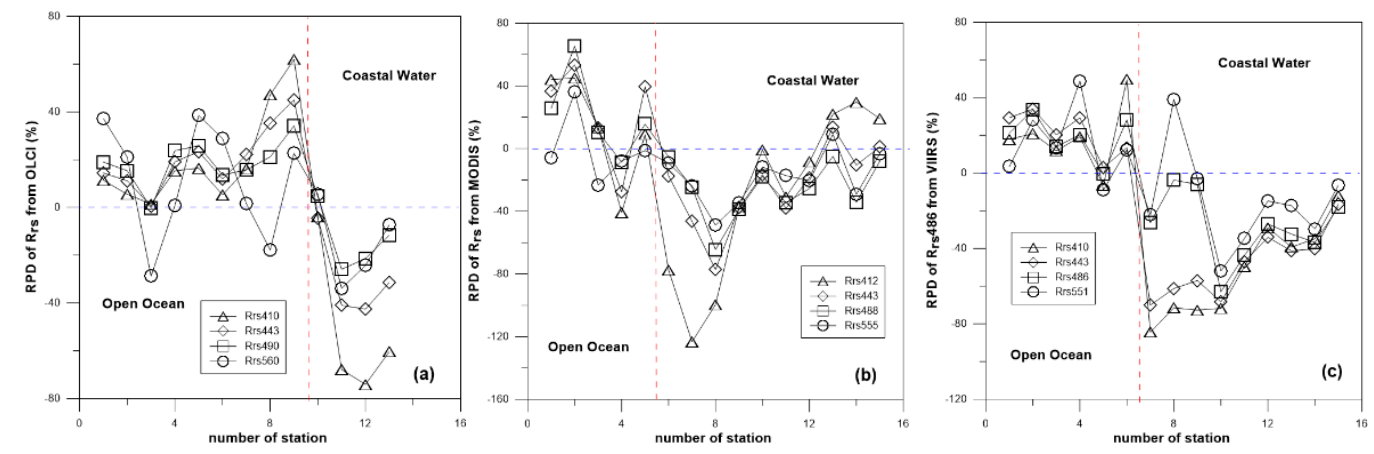

Figure 9. RPD of $R_{r s}$ at each station from OLCI (a), MODIS (b), VIIRS (c). The vertical red dashed line shows the limit between the open and coastal waters.

\section{Discussion}

Few works exist that the error of $R_{r s}(\lambda)$ from in-situ data [34,50,68]. The error of $R_{r s}(\lambda)$ from BOUSSOLE was reported to be $6 \%$ in the VIS bands [68], and the error of in-situ data from AERONET-OC was approximately $5 \%$ from $412 \mathrm{~nm}$ to $551 \mathrm{~nm}$, and $8 \%$ at $667 \mathrm{~nm}$ [34]. The difference between directly measured $R_{r s}(\lambda)$ and $R_{r s}(\lambda)$ obtain using the optimization approach (bio-optical model) is 
approximately $11 \%$ in all bands [50]. The data in Figure 3 show that the difference in $R_{r s}(\lambda)$ between the GSM model and the in-situ data is approximately $14 \%$ in the VIS bands and $26 \%$ in the NIR bands. We assume that the error of $R_{r s}(\lambda)$ from the GSM model is the same as the error of the in-situ data. Then, using Equation (3), the error of in-situ $R_{r s}(\lambda)$ is $7 \%$ in the VIS bands and $13 \%$ in the NIR bands.

As discussed in Section 2.2, we estimated an error budget. We used 754,678, and $671 \mathrm{~nm}$ as the NIR bands for OLCI, MODIS, and VIIRS, respectively, due to the lack of $R_{r S}(N I R)$ in standard MODIS and VIIRS products. We first calculated the error of $R_{r s}$ and the error of the iterative model; then, we calculated the percentage of the error of the iterative model in the error of $R_{r s}$. Finally, we calculated the average result according to the location of stations (open ocean or coastal waters). We investigated the factors that impacted the errors on the estimation of $R_{r s}$ in the open ocean and coastal waters using the equation presented in Section 2.2.

\subsection{Influencing Factors in the Open Ocean}

The mean error of $R_{r s}$ for the three sensors in the open ocean is shown in Figure 10a, revealing that the three sensors have similar $R_{r s}$ errors, all of which are relatively high in the blue band (approximately $0.0008 \mathrm{sr}^{-1}$ ) and then decrease as the band increases (falling to approximately $0.0002 \mathrm{sr}^{-1}$ for the red band). In terms of numerical values, VIIRS shows the highest error, followed by OLCI and MODIS, which show the lowest errors at 443 and $486 \mathrm{~nm}$, respectively. The $400 \mathrm{~nm}$ band of OLCI has the largest error.
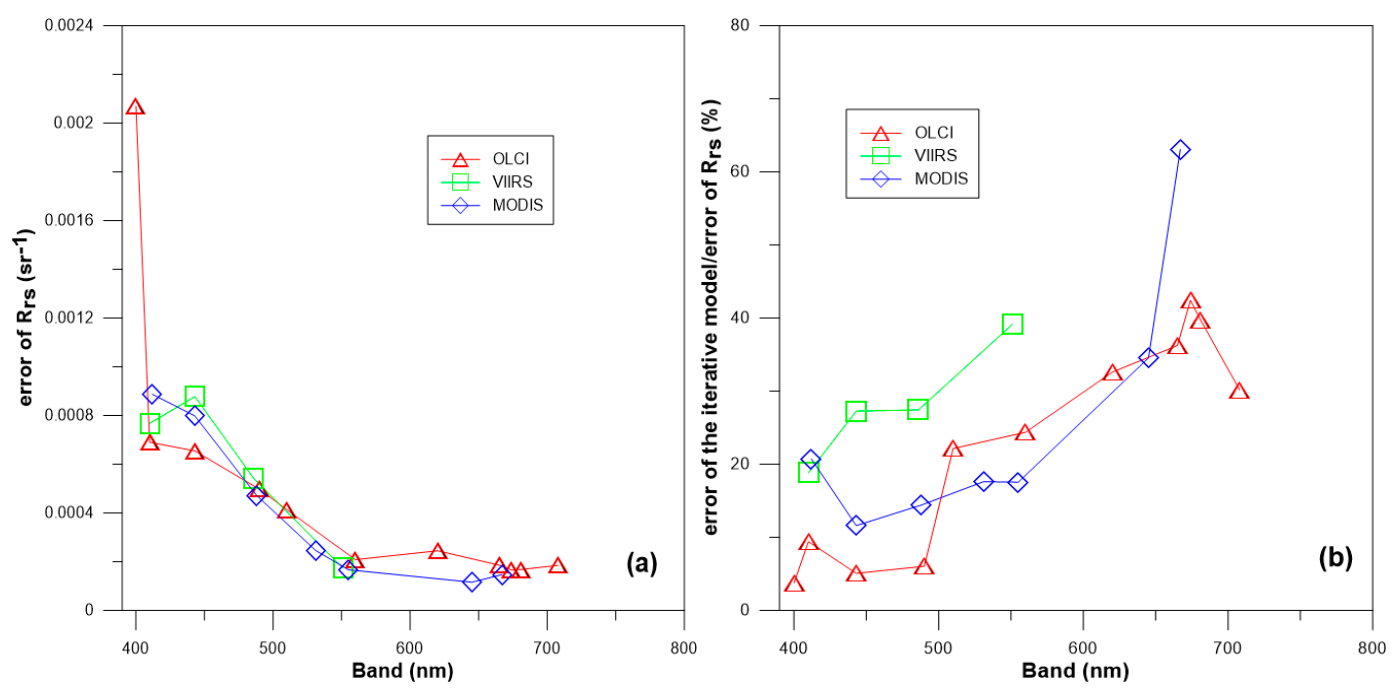

Figure 10. Mean error of $R_{r s}$ from OLCI, MODIS, and VIIRS in open ocean (a) and the mean percentage of the error of the iterative model in the error of $R_{r s}$ from OLCI, MODIS, and VIIRS in the open ocean (SCS) (b).

The mean percentage of the iterative model error in the error of $R_{r s}$ over the open ocean is shown in Figure 10b, showing that the percentages of the iterative model error in the error of $R_{r s}$ from the three sensors have similar trends, all have high percentages in the red bands and lower values in the blue band, except for $410 \mathrm{~nm}$ (OLCI) and $412 \mathrm{~nm}$ (MODIS). The ratio of the iteration error of OLCI is less than that MODIS and VIIRS in the bands before $500 \mathrm{~nm}$. For the open ocean region of the China Sea, the ratio of the iteration error of the three satellites from 400 to $600 \mathrm{~nm}$ in the total error is less than $50 \%$, which indicates that the main influencing factors of the three satellites are not the iterative algorithm, but the aerosols LUTs $\left(\delta L_{A}(\lambda)\right)$ [65] and the Rayleigh-corrected radiance $\left(\delta L_{r c}(\lambda)\right)$. This conclusion was also reached by Zibordi et al. (2018) [20]. 


\subsection{Influencing Factors in the Coastal Waters}

Similar operations were conducted for coastal waters. The mean error of $R_{r s}$ for the three sensors in the coastal waters is shown in Figure 11a. The figure shows that the $R_{r s}$ error trends of the three satellites are similar to those in the open ocean, but the blue bands show different behaviors. In the bands shorter than $500 \mathrm{~nm}$, the $R_{r s}$ error of OLCI is the highest, and the $R_{r s}$ error of MODIS is the smallest. For bands above $510 \mathrm{~nm}$, the $R_{r s}$ error of OLCI and MODIS are both less than the $R_{r s}$ error of VIIRS. We can also observe that the $R_{r s}$ error of OLCI increases at the 410 and $443 \mathrm{~nm}$ bands. The $R_{r s}$ errors of the three satellites over coastal waters are higher than those over open ocean, especially for OLCI in bands shorter than $450 \mathrm{~nm}$.
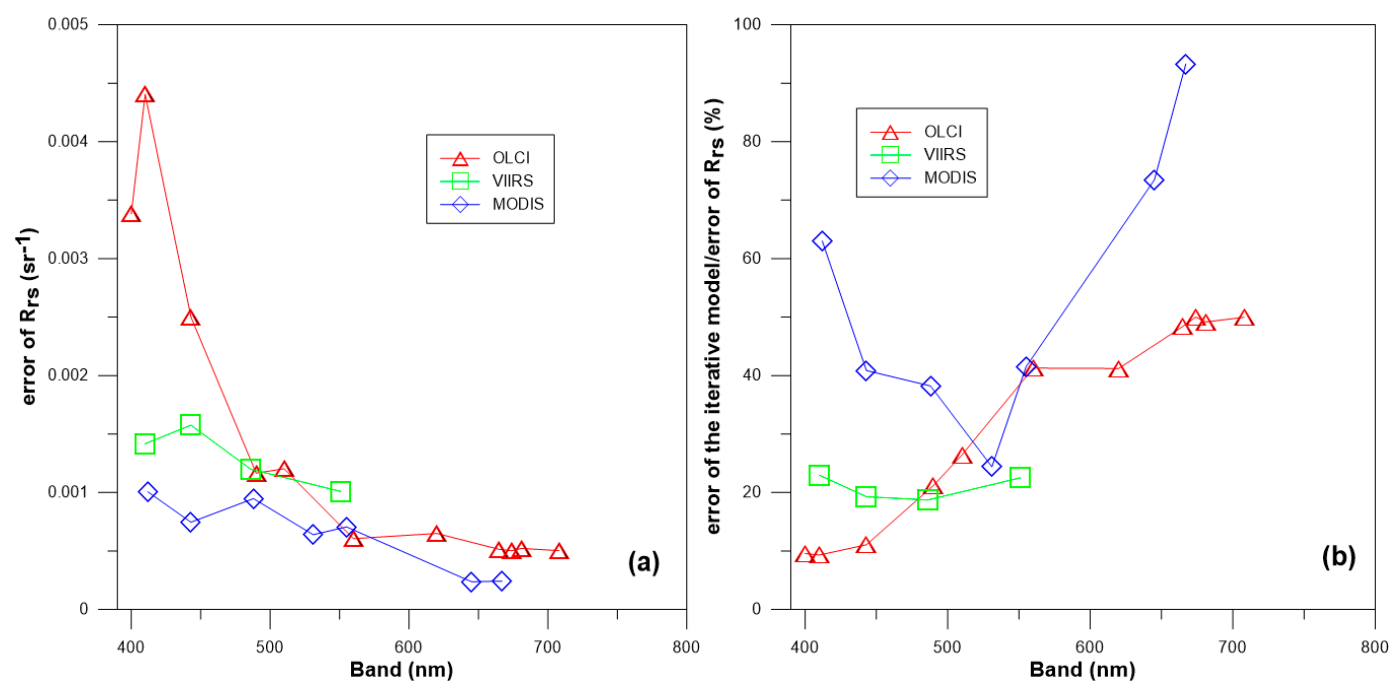

Figure 11. Mean error of $R_{r s}$ from OLCI, MODIS, and VIIRS in coastal water (a) and the mean percentage of the error of the iterative model in the error of $R_{r s}$ from OLCI, MODIS, and VIIRS in coastal water (b).

The mean percentage of the error of the iterative model in the error of $R_{r s}$ in the coastal waters is shown in Figure 11b, where the iterative algorithm error of MODIS has the highest proportion in the total error of $R_{r s}$ except at $531 \mathrm{~nm}$, and it is less than $50 \%$ from 440 to $555 \mathrm{~nm}$, which are the main VIS bands, while the ratio of the iterative algorithm error of OLCI and VIIRS is less than $50 \%$ in the total error of $R_{r s}$ in all bands. Although the impact of the iterative algorithm on the $R_{r s}$ error is higher in MODIS, the aerosol estimation and the error of the Rayleigh-corrected radiance in the coastal waters remain the major error sources for all three sensors over coastal waters.

\section{Summary}

The OLCI, MODIS, and VIIRS $R_{r s}$ products were evaluated against in situ measurements through a match-up analysis in the China Sea. This analysis showed that the satellite-derived- $R_{r s}$ are in good agreement with the in-situ data and that the $R_{r s}$ from the three sensors are overestimated over the open ocean and underestimated over the coastal waters around China. The highest uncertainty was observed in the NIR bands for the three missions. The bands with the best performances for the three missions were all between 488 and $560 \mathrm{~nm}$, which agree with the results of previous studies. The performance of OLCI is good (the APD of $R_{r s}$ at $490 \mathrm{~nm}$ is the most accurate with values of $18 \%$ ) and close to or better than MODIS (the APD of $R_{r s}$ at $531 \mathrm{~nm}$ is the most accurate with values of 19\%) around the China Sea.

The calculated error budget showed that the iterative model used in the atmospheric correction algorithm of OLCI has a smaller impact on the error of $R_{r s}$ compared to the NASA iterative model used to process the MODIS and VIIRS data over the open ocean around China. The main influencing factors on the error of $R_{r s}$ for OLCI, MODIS, and VIIRS are the aerosol LUTs and the Rayleigh-corrected radiance (the error of system vicarious calibration, the error of Rayleigh scattering, whitecaps, gas and 
glint correction algorithm, and surface effects [51,66]) used in the atmospheric correction algorithm over the open ocean and coastal waters around the China Sea.

Author Contributions: J.L. conceived the idea and wrote the manuscript. J.L. and C.J. discussed and revised the manuscript. J.L., J.Z., B.H., T.L., A.Y., K.G., and D.J. processed the in-situ data.

Funding: This study was supported by the following funding:(1) The National Key Research and Development Program of China (2016YFC1400906); (2) The National Key Research and Development Program of China (2016YFC1400903); (3) Operational Support Service System for Natural Resources Satellite Remote Sensing.

Acknowledgments: The authors would like to thank ESA and NASA for the distribution of OLCI, MODIS, and VIIRS data products. Thanks also go to the reviewers for thorough comments that really helped to improve the manuscript.

Conflicts of Interest: The authors declare no conflict of interest.

\section{References}

1. Alvain, S.; Moulin, C.; Dandonneau, Y.; Loisel, H. Seasonal distribution and succession of dominant phytoplankton groups in the global ocean: A satellite view. Glob. Biogeochem. Cycles 2008, 22, 22. [CrossRef]

2. Sathyendranath, S.; Aiken, J.; Alvain, S.; Barlow, R.; Bouman, H.; Bracher, A.; Brewin, R.; Bricaud, A.; Brown, C.; Ciotti, A. Phytoplankton functional types from Space. In Reports of the International Ocean-Colour Coordinating Group (IOCCG); 15; International Ocean-Colour Coordinating Group: Bedford, NS, Canada, 2014; pp. 1-156.

3. Ahn, J.H. Size distribution and settling velocities of suspended particles in a tidal embayment. Water Res. 2012, 46, 3219-3228. [CrossRef] [PubMed]

4. Boss, E.; Pegau, W.S. Relationship of light scattering at an angle in the backward direction to the backscattering coefficient. Appl. Opt. 2001, 40, 5503-5507. [CrossRef]

5. Buesseler, K.O.; Lamborg, C.H.; Boyd, P.W.; Lam, P.J.; Trull, T.W.; Bidigare, R.R.; Bishop, J.K.; Casciotti, K.L.; Dehairs, F.; Elskens, M. Revisiting carbon flux through the ocean's twilight zone. Science 2007, 316, 567-570. [CrossRef]

6. Quere, C.L.; Harrison, S.P.; Colin Prentice, I.; Buitenhuis, E.T.; Aumont, O.; Bopp, L.; Claustre, H.; Cotrim Da Cunha, L.; Geider, R.; Giraud, X.; et al. Ecosystem dynamics based on plankton functional types for global ocean biogeochemistry models. Glob. Chang. Biol. 2005, 11, 2016-2040. [CrossRef]

7. Twardowski, M.S.; Boss, E.; Macdonald, J.B.; Pegau, W.S.; Barnard, A.H.; Zaneveld, J.R.V. A model for estimating bulk refractive index from the optical backscattering ratio and the implications for understanding particle composition in case I and case II waters. J. Geophys. Res. Ocean. 2001, 106, 14129-14142. [CrossRef]

8. Hooker, S.; McClain, C. The calibration and validation of SeaWiFS data. Prog. Oceanogr. 2000, 45, 427-465. [CrossRef]

9. Morel, A.; Huot, Y.; Gentili, B.; Werdell, P.J.; Hooker, S.B.; Franz, B.A. Examining the consistency of products derived from various ocean color sensors in open ocean (Case 1) waters in the perspective of a multi-sensor approach. Remote Sens. Environ. 2007, 111, 69-88. [CrossRef]

10. Frouin, R.; Sei, A.; Hauss, B.; Pratt, P. Operational in-flight calibration of S-NPP VIIRS in the visible using Rayleigh scattering. In Proceedings of the SPIE 9218, Earth Observing Systems XIX, San Diego, CA, USA, 2 October 2014; Volume 921806.

11. Wang, M. Atmospheric correction for remotely-sensed ocean-colour products. In Reports of the International Ocean-Colour Coordinating Group (IOCCG); 10; International Ocean-Colour Coordinating Group: Bedford, NS, Canada, 2010; pp. 1-83.

12. Jamet, C.; Loisel, H.; Kuchinke, C.P.; Ruddick, K.; Zibordi, G.; Feng, H. Comparison of three SeaWiFS atmospheric correction algorithms for turbid waters using AERONET-OC measurements. Remote Sens. Environ. 2011, 115, 1955-1965. [CrossRef]

13. Goyens, C.; Jamet, C.; Schroeder, T. Evaluation of four atmospheric correction algorithms for MODIS-Aqua images over contrasted coastal waters. Remote Sens. Environ. 2013, 131, 63-75. [CrossRef]

14. Zibordi, G.; Mélin, F.; Voss, K.J.; Johnson, B.C.; Franz, B.A.; Kwiatkowska, E.; Huot, J.-P.; Wang, M.; Antoine, D. System vicarious calibration for ocean color climate change applications: Requirements for in-situ data. Remote Sens. Environ. 2015, 159, 361-369. [CrossRef] 
15. Platt, T.; Hoepffner, N.; Stuart, V.; Brown, C. Why Ocean Colour? The Societal Benefits of Ocean-Colour Technology. In Reports of the International Ocean-Colour Coordinating Group (IOCCG); 7; International Ocean-Colour Coordinating Group: Bedford, NS, Canada, 2008; pp. 1-138.

16. Greb, S.; Dekker, A.; Binding, C. Earth Observations in Support of Global Water Quality. In Reports of the International Ocean-Colour Coordinating Group (IOCCG); 17; International Ocean-Colour Coordinating Group: Bedford, NS, Canada, 2018; pp. 1-25.

17. Berruti, D.; Ferreira, B.; Femenias, M.H. The Global Monitoring for Environment and Security (GMES) Sentinel-3 mission. Remote Sens. Environ. 2012, 120, 37-57.

18. Malenovský, Z.; Rott, H.; Cihlar, J.; Schaepman, M.E.; García-Santos, G.; Fernandes, R.; Berger, M. Sentinels for science: Potential of Sentinel-1, -2 , and -3 missions for scientific observations of ocean, cryosphere, and land. Remote Sens. Environ. 2012, 120, 91-101. [CrossRef]

19. Shen, M.; Duan, H.; Cao, Z.; Xue, K.; Loiselle, S.; Yesou, H. Determination of the downwelling diffuse attenuation coefficient of lake water with the Sentinel-3A OLCI. Remote Sens. 2017, 9, 1246. [CrossRef]

20. Zibordi, G.; Mélin, F.; Berthon, J.-F. A regional assessment of OLCI data products. IEEE Geosci. Remote Sens. Lett. 2018, 15, 1490-1494. [CrossRef]

21. Mograne, M.A.; Jamet, C.; Loisel, H.; Vantrepotte, V.; Mériaux, X.; Cauvin, A. Evaluation of Five Atmospheric Correction Algorithms over French Optically-Complex Waters for the Sentinel-3A OLCI Ocean Color Sensor. Remote Sens. 2019, 11, 668. [CrossRef]

22. Gossn, J.I.; Ruddick, K.G.; Dogliotti, A.I. Atmospheric Correction of OLCI Imagery over Extremely Turbid Waters Based on the Red, NIR and 1016 nm Bands and a New Baseline Residual Technique. Remote Sens. 2019, 11, 220. [CrossRef]

23. Gordon, H.R.; Wang, M. Retrieval of water-leaving radiance and aerosol optical thickness over the oceans with SeaWiFS: A preliminary algorithm. Appl. Opt. 1994, 33, 443-452. [CrossRef]

24. Bailey, S.W.; Franz, B.A.; Werdell, P.J. Estimation of near-infrared water-leaving reflectance for satellite ocean color data processing. Opt. Express 2010, 18, 7521-7527. [CrossRef]

25. Ahmad, Z.; Fraser, R.S. An iterative radiative transfer code for ocean-atmosphere systems. J. Atmos. Sci. 1982, 39, 656-665. [CrossRef]

26. Cox, C.; Munk, W. Measurement of the roughness of the sea surface from photographs of the sun's glitter. Josa 1954, 44, 838-850. [CrossRef]

27. Bodhaine, B.A.; Wood, N.B.; Dutton, E.G.; Slusser, J.R. On Rayleigh optical depth calculations. J. Atmos. Ocean. Technol. 1999, 16, 1854-1861. [CrossRef]

28. Koepke, P. Effective reflectance of oceanic whitecaps. Appl. Opt. 1984, 23, 1816-1824. [CrossRef] [PubMed]

29. Frouin, R.; Schwindling, M.; Deschamps, P.Y. Spectral reflectance of sea foam in the visible and near-infrared: In situ measurements and remote sensing implications. J. Geophys. Res. Ocean. 1996, 101, 14361-14371. [CrossRef]

30. Stramska, M.; Petelski, T. Observations of oceanic whitecaps in the north polar waters of the Atlantic. J. Geophys. Res. Ocean. 2003, 108. [CrossRef]

31. Ahmad, Z.; McClain, C.R.; Herman, J.R.; Franz, B.A.; Kwiatkowska, E.J.; Robinson, W.D.; Bucsela, E.J.; Tzortziou, M. Atmospheric correction for NO 2 absorption in retrieving water-leaving reflectances from the SeaWiFS and MODIS measurements. Appl. Opt. 2007, 46, 6504-6512. [CrossRef]

32. Ding, K.; Gordon, H.R. Analysis of the influence of $\mathrm{O} 2$ A-band absorption on atmospheric correction of ocean-color imagery. Appl. Opt. 1995, 34, 2068-2080. [CrossRef]

33. Ahmad, Z.; Franz, B.A.; McClain, C.R.; Kwiatkowska, E.J.; Werdell, J.; Shettle, E.P.; Holben, B.N. New aerosol models for the retrieval of aerosol optical thickness and normalized water-leaving radiances from the SeaWiFS and MODIS sensors over coastal regions and open oceans. Appl. Opt. 2010, 49, 5545-5560. [CrossRef]

34. Zibordi, G.; Berthon, J.-F.; Mélin, F.; D’Alimonte, D.; Kaitala, S. Validation of satellite ocean color primary products at optically complex coastal sites: Northern Adriatic Sea, Northern Baltic Proper and Gulf of Finland. Remote Sens. Environ. 2009, 113, 2574-2591. [CrossRef]

35. Zibordi, G.; Mélin, F.; Berthon, J.-F.; Holben, B.; Slutsker, I.; Giles, D.; D'Alimonte, D.; Vandemark, D.; Feng, H.; Schuster, G. AERONET-OC: A network for the validation of ocean color primary products. J. Atmos. Ocean. Technol. 2009, 26, 1634-1651. [CrossRef] 
36. Antoine, D.; Morel, A. A multiple scattering algorithm for atmospheric correction of remotely sensed ocean colour (MERIS instrument): Principle and implementation for atmospheres carrying various aerosols including absorbing ones. Int. J. Remote Sens. 1999, 20, 1875-1916. [CrossRef]

37. Moore, G.; Aiken, J.; Lavender, S. The atmospheric correction of water colour and the quantitative retrieval of suspended particulate matter in Case II waters: Application to MERIS. Int. J. Remote Sens. 1999, 20, 1713-1733. [CrossRef]

38. Stumpf, R.; Arnone, R.; Gould, R.; Martinolich, P.; Ransibrahmanakul, V. A partially coupled ocean- atmosphere model for retrieval of water-leaving radiance from SeaWiFS in coastal waters. NASA Technol. Memo 2003, 206892, 51-59.

39. Wang, M. Remote sensing of the ocean contributions from ultraviolet to near-infrared using the shortwave infrared bands: Simulations. Appl. Opt. 2007, 46, 1535-1547. [CrossRef] [PubMed]

40. Lavender, S.; Pinkerton, M.; Moore, G.; Aiken, J.; Blondeau-Patissier, D. Modification to the atmospheric correction of SeaWiFS ocean colour images over turbid waters. Cont. Shelf Res. 2005, 25, 539-555. [CrossRef]

41. Taylor, B.N.; Kuyatt, C.E. Guidelines for evaluating and expressing the uncertainty of NIST measurement results. In National Institute of Standards and Technology Technical Note 1297; Diane Publishing, US Government Printing Office: Washington, DC, USA, 1994.

42. Taylor, J.R. The study of uncertainties in physical measurements. In An Introduction to Error Analysis; University of Colorado: Boulder, CO, USA, 1982; Volume 73.

43. Yang, H.; Gordon, H.R. Remote sensing of ocean color: Assessment of water-leaving radiance bidirectional effects on atmospheric diffuse transmittance. Appl. Opt. 1997, 36, 7887-7897. [CrossRef]

44. Shettle, E.P.; Fenn, R.W. Models for the Aerosols of the Lower Atmosphere and the Effects of Humidity Variations on Their Optical Properties; Air Force Geophysics Lab Hanscom Afb Ma: Washington, DC, USA, 1979.

45. Zibordi, G.; Mélin, F.; Hooker, S.B.; D’Alimonte, D.; Holben, B. An autonomous above-water system for the validation of ocean color radiance data. IEEE Trans. Geosci. Remote Sens. 2004, 42, 401-415. [CrossRef]

46. Mueller, J.L.; Morel, A.; Frouin, R.; Davis, C.; Arnone, R.; Carder, K.; Lee, Z.; Steward, R.; Hooker, S.; Mobley, C. Ocean Optics Protocols for Satellite Ocean Color Sensor Validation, Revision 4. Volume III: Radiometric Measurements and Data Analysis Protocols; Goddard Space Flight Space Center: Greenbelt, MA, USA, 2003.

47. Ruddick, K.G.; De Cauwer, V.; Park, Y.-J.; Moore, G. Seaborne measurements of near infrared water-leaving reflectance: The similarity spectrum for turbid waters. Limnol. Oceanogr. 2006, 51, 1167-1179. [CrossRef]

48. Garaba, S.; Zielinski, O. Methods in reducing surface reflected glint for shipborne above-water remote sensing. J. Eur. Opt. Soc.-Rapid Publ. 2013, 8, 8. [CrossRef]

49. Werdell, P.J.; McKinna, L.I.; Boss, E.; Ackleson, S.G.; Craig, S.E.; Gregg, W.W.; Lee, Z.; Maritorena, S.; Roesler, C.S.; Rousseaux, C.S. An overview of approaches and challenges for retrieving marine inherent optical properties from ocean color remote sensing. Prog. Oceanogr. 2018, 160, 186-212. [CrossRef]

50. Lee, Z.; Ahn, Y.-H.; Mobley, C.; Arnone, R. Removal of surface-reflected light for the measurement of remote-sensing reflectance from an above-surface platform. Opt. Express 2010, 18, 26313-26324. [CrossRef]

51. Gilerson, A.; Carrizo, C.; Foster, R.; Harmel, T. Variability of the reflectance coefficient of skylight from the ocean surface and its implications to ocean color. Opt. Express 2018, 26, 9615-9633. [CrossRef] [PubMed]

52. Moon, J.-E.; Park, Y.-J.; Ryu, J.-H.; Choi, J.-K.; Ahn, J.-H.; Min, J.-E.; Son, Y.-B.; Lee, S.-J.; Han, H.-J.; Ahn, Y.-H. Initial validation of GOCI water products against in-situ data collected around Korean peninsula for 2010-2011. Ocean Sci. J. 2012, 47, 261-277. [CrossRef]

53. Gordon, H.R.; Brown, O.B.; Evans, R.H.; Brown, J.W.; Smith, R.C.; Baker, K.S.; Clark, D.K. A semianalytic radiance model of ocean color. J. Geophys. Res. Atmos. 1988, 93, 10909-10924. [CrossRef]

54. Lee, Z. Remote sensing of inherent optical properties: Fundamentals, tests of algorithms, and applications. In Reports of the International Ocean-Colour Coordinating Group (IOCCG); 5; International Ocean-Colour Coordinating Group: Bedford, NS, Canada, 2006; pp. 1-122.

55. Garver, S.A.; Siegel, D.A. Inherent optical property inversion of ocean color spectra and its biogeochemical interpretation: 1. Time series from the Sargasso Sea. J. Geophys. Res. Ocean. 1997, 102, 18607-18625. [CrossRef]

56. Maritorena, S.; Siegel, D.A.; Peterson, A.R. Optimization of a semianalytical ocean color model for global-scale applications. Appl. Opt. 2002, 41, 2705-2714. [CrossRef] [PubMed] 
57. Lee, Z.; Shang, S.; Lin, G.; Chen, J.; Doxaran, D. On the modeling of hyperspectral remote-sensing reflectance of high-sediment-load waters in the visible to shortwave-infrared domain. Appl. Opt. 2016, 55, 1738-1750. [CrossRef] [PubMed]

58. Werdell, P.J.; Bailey, S.W.; Franz, B.A.; Morel, A.; McClain, C.R. On-orbit vicarious calibration of ocean color sensors using an ocean surface reflectance model. Appl. Opt. 2007, 46, 5649-5666. [CrossRef]

59. Barnes, B.B.; Cannizzaro, J.P.; English, D.C.; Hu, C. Validation of VIIRS and MODIS reflectance data in coastal and oceanic waters: An assessment of methods. Remote Sens. Environ. 2019, 220, 110-123. [CrossRef]

60. Bailey, S.W.; Werdell, P.J. A multi-sensor approach for the on-orbit validation of ocean color satellite data products. Remote Sens. Environ. 2006, 102, 12-23. [CrossRef]

61. Mélin, F.; Sclep, G.; Jackson, T.; Sathyendranath, S. Uncertainty estimates of remote sensing reflectance derived from comparison of ocean color satellite data sets. Remote Sens. Environ. 2016, 177, 107-124. [CrossRef]

62. Zhao, W.; Wang, G.; Cao, W.; Cui, T.; Wang, G.; Ling, J.; Sun, L.; Zhou, W.; Sun, Z.; Xu, Z. Assessment of SeaWiFS, MODIS, and MERIS ocean colour products in the South China Sea. Int. J. Remote Sens. 2014, 35, 4252-4274. [CrossRef]

63. Sun, D.; Qiu, Z.; Hu, C.; Wang, S.; Wang, L.; Zheng, L.; Peng, T.; He, Y. A hybrid method to estimate suspended particle sizes from satellite measurements over B ohai S ea and Y ellow S ea. J. Geophys. Res. Ocean. 2016, 121, 6742-6761. [CrossRef]

64. Wei, J.; Lee, Z.; Shang, S. A system to measure the data quality of spectral remote-sensing reflectance of aquatic environments. J. Geophys. Res. Ocean. 2016, 121, 8189-8207. [CrossRef]

65. Kahn, R.A.; Sayer, A.M.; Ahmad, Z.; Franz, B.A. The sensitivity of SeaWiFS ocean color retrievals to aerosol amount and type. J. Atmos. Ocean. Technol. 2016, 33, 1185-1209. [CrossRef]

66. Gordon, H.R.; Wang, M. Surface-roughness considerations for atmospheric correction of ocean color sensors. 1: The Rayleigh-scattering component. Appl. Opt. 1992, 31, 4247-4260. [CrossRef]

67. Carrizo, C.; Gilerson, A.; Foster, R.; Golovin, A.; El-Habashi, A. Characterization of radiance from the ocean surface by hyperspectral imaging. Opt. Express 2019, 27, 1750-1768. [CrossRef]

68. Antoine, D.; d'Ortenzio, F.; Hooker, S.B.; Bécu, G.; Gentili, B.; Tailliez, D.; Scott, A.J. Assessment of uncertainty in the ocean reflectance determined by three satellite ocean color sensors (MERIS, SeaWiFS and MODIS-A) at an offshore site in the Mediterranean Sea (BOUSSOLE project). J. Geophys. Res. Ocean. 2008, 113, 113. [CrossRef] 